\title{
CRÓNICA DEL TRABAJO DEL RELATOR ESPECIAL SOBRE LA EXPULSIÓN DE EXTRANJEROS DE LA COMISIÓN DE DERECHO INTERNACIONAL DE LAS NACIONES UNIDAS (2004-2014)*
}

\author{
Lila García** \\ Recibido: Marzo 8 de 2017 \\ Aprobado: Mayo 10 \\ de 2017
}

\section{RESUMEN}

La expulsión de personas extranjeras ha permanecido como un tema con limitada regulación por parte del derecho internacional; sin embargo, existe consenso en que uno de los límites modernos a la facultad del Estado de expulsar a personas extranjeras está dado por las normas de derechos humanos. En pos de identificar, codificar y desarrollar estas regulaciones es que viene el trabajo del Relator Especial sobre la Expulsión de Extranjeros de la Comisión de Derecho Internacionales (CDI) de Naciones Unidas, iniciado en 2004 y finalizado en 2014 y que ha pasado prácticamente desapercibido tanto para los estudio de migraciones como para los desarrollos del derecho internacional. Así, este artículo se propone revisar estos diez años de labor principalmente a través del análisis documental de fuentes primarias (informes del Relator, los debates al interior de la CDI y su eco en la Sexta Comisión de la Asamblea General) a fin de contar con un panorama general de la labor, identificar las discusiones medulares y los resultados alcanzados y analizar si esta perspectiva de derechos humanos conmueve los puntos de partida de la soberanía estatal en torno a la extranjería. Todo ello, de cara al próximo debate del proyecto de artículos que la Asamblea General hará durante su 72va sesión en este 2017.

Palabras clave: Extranjeros, expulsión, derechos humanos, migración, Naciones Unidas.

* Mil agradecimientos a mi colega Brian Frenkel, quien llamó mi atención sobre le trabajo del Relator.

**Doctora en Derecho (Área Derecho Internacional), Universidad Nacional de Buenos Aires. Investigadora Del Consejo Nacional de Investigaciones Científicas y Técnicas (CONICET), UNMdP. E-mail: garcia.lila@gmail.com 


\title{
CHRONICLE OF THE SPECIAL RAPPORTEUR OF THE INTERNATIONAL LAW COMMISSION ABOUT THE EXPULSION OF FOREIGNERS
}

\begin{abstract}
The expulsion of foreigners has remained a topic with limited regulation by international law; however, there exits consensus that one of the modern limits to the State's power to expel foreigners is given by human rights. In order to identify, codify and develop these regulations it is possible to point out the work of the Special Rapporteur of the international law commission about the expulsion of foreigners (CDI) that began in 2004 and ended in 2014 and that has passed almost unnoticed by migration and international law develpments. Thus, this text proposes to review these ten years of work, mainly through documentary analysis of primary sources (reports, debates within the ILC and its echo in the Sixth Commission of the General Assembly) in order to make an overview of the work, identify the fundamental discussions and the results achieved and to analyze whether this perspective of human rights affects the position of state sovereignty concerning foreigners. All this, with a view to the next debate of the project that will take place within the 72 nd session of the General Assembly in 2017.
\end{abstract}

Key words: Foreigners; expulsion; human rights; migration; United Nations

\section{CRÔNICA DO TRABALHO DO RELATOR ESPECIAL SOBRE A EXPULSÃO DE ESTRANGEIROS DA COMISSÃO DE DIREITO INTERNACIONAL DAS NAÇÕES UNIDAS (2004- 2014)}

\section{RESUMO}

A expulsão de pessoas estrangeiras tem permanecido como um assunto com regulamentação limitada pelo direito internacional; no entanto, existe consenso de que um dos limites modernos sobre o poder do Estado para expulsar pessoas estrangeiras é dada pelas normas de direitos humanos.

Depois de identificar, codificar e desenvolver estes regulamentos vem o trabalho do Relator Especial sobre a expulsão de estrangeiros da Comissão de Direito Internacional (CDI) da Organização das Nações 
Unidas, lançado em 2004 e concluída em 2014 e que passou praticamente despercebida tanto para o estudo das migrações como para o desenvolvimento do direito internacional. Assim, este artigo pretende rever estes dez anos de trabalho principalmente através da análise documental de fontes primárias (relatórios do relator, as discussões no seio da Comissão e seu eco na Sexta Comissão da Assembleia Geral) para ter uma visão geral do trabalho, identificar discussões centrais e os resultados alcançados e analisar se esta perspectiva dos direitos humanos comove os pontos de partida da soberania do estado em torno aos estrangeiros. Tudo isso, para a próxima discussão do projeto de artigos que a Assembleia Geral fará durante a sessão 72va neste 2017 .

Palavras-chave: Estrangeiros, Expulsão, Direitos Humanos, Migração, Nações Unidas

\section{PRESENTACIÓN}

La expulsión de personas extranjeras por parte de un Estado distinto al de su nacionalidad y en general, el trato de este hacia sus poblaciones no nacionales, ha permanecido como un tema con baja regulación por el derecho internacional público (DIP). De hecho, se ubica en los grises de los márgenes de discrecionalidad del Estado y se ha considerado "demasiado sensible como para regularlo mediante instrumentos multilaterales vinculantes" (Comisión de Derecho Internacional, 2006). Las personas extranjeras representan, en ese sentido, uno de los últimos bastiones de resistencia a la fiscalización internacional: si hasta 1945 el trato que un Estado daba a sus nacionales se consideraba una cuestión doméstica, uno de los últimos grupos poblacionales sobre los cuales se libra una disputa entre las determinaciones domésticas y las regulaciones internacionales y dentro de estas últimas, sobre cuál es el régimen aplicable es, precisamente, el de personas extranjeras y especialmente migrantes. Incluso, veremos, las mismas referencias desde el Derecho Internacional de los Derechos Humanos (DIDH) dejan buena parte de las cuestiones libradas al orden interno.

En el DIP clásico, la visibilidad del individuo quedaba mediada por el Estado; (Sorensen. 1975, p. 275) cuando la política se hace cargo de la vida de la porción de población que se asigna ("nación"), esta protección fue primero ejercida con exclusividad por el Estado: al interior, bajo el principio de no injerencia en los asuntos de jurisdicción interna; al exterior, bajo la protección diplomática de sus nacionales frente a terceros Estados o al menos, ante a los Estados respecto de los cuales el 
nacional resultara extranjero pero convenían, básicamente, en respetarse mutuamente en la persona de sus nacionales.(Pinto, 2004)

Este panorama tuvo como resultado el ubicar a las poblaciones en movimiento como elementos díscolos (en un plan donde lo normal se vuelve el ser natural de un cierto país) y luego problemáticos, por ser entendida en primer lugar como un elemento de otro Estado presente en territorio nacional y alcanzada, por tanto, por las lógicas de la lealtad a la patria, los juegos de espionaje y la sospecha y de allí, que la cuestión se encuadrara como de seguridad y orden públicos, cláusulas estrella en los motivos para expulsar personas extranjeras.

Frente a esta visión, el DIDH propone desplazar el foco en el Estado y su soberanía y ubicarlo en la persona en situación de movilidad. Encontramos en este recorrido desde el derecho de asilo que, con carácter general, reconocen las Declaraciones americana y universal hasta las cláusulas de no discriminación por nacionalidad que inauguran los principales tratados de derechos humanos aunque, más específicamente, la mención de las personas extranjeras sólo incluye a aquellas en situación legal ${ }^{1}$, esto es, de aquellas respecto de las cuales el Estado ya ha dado su anuencia. A tal punto las previsiones generales sobre no discriminación o sobre "toda persona" no se aplicaban a personas extranjeras que una declaración en $1985^{2}$ viene a recordar un set de derechos que todas las personas (en particular, aquellas que "no son nacionales del país donde viven") ostentan por serlo. Poco después, el Comité de Derechos Humanos emite su comentario general número 15 , relativo a la situación de los "extranjeros" con arreglo al Pacto.

Luego, los esfuerzos sino de todos los órganos de las UN al menos de la Asamblea General de Naciones Unidas, se vuelcan hacia los "trabajadores migratorios", abriendo a la firma en 1990 la convención respectiva $(\mathrm{CTM})^{3}$. Esta convención, pese a contener algunos estándares que son incluso menores a los convenios generales de derechos humanos, encontró fuerte resistencia por parte de los Estados al punto de

1. Art. 12, Pacto Internacional de Derechos Civiles y Políticos: "1. Toda persona que se halle legalmente en el territorio de un Estado tendrá derecho a circular libremente por él y a escoger libremente en él su residencia..."; art. 13 PIDCyP: "El extranjero que se halle legalmente en el territorio de un Estado Parte en el presente Pacto sólo podrá ser expulsado de él en cumplimiento de una decisión adoptada conforme a la ley...". Art. 22 Convención Americana sobre Derechos Humanos: "1. Toda persona que se halle legalmente en el territorio de un Estado tiene derecho a circular por el mismo y, a residir en él con sujeción a las disposiciones legales...” y “6. El extranjero que se halle legalmente en el territorio de un Estado parte en la presente Convención, sólo podrá ser expulsado de él en cumplimiento de una decisión adoptada conforme a la ley".

2. Asamblea General de Naciones Unidas, Declaración sobre los derechos humanos de los individuos que no son nacionales del país en que viven, Resolución 40/144, de 13 de diciembre de 1985

3. Convención Internacional sobre la protección de todos los derechos de los trabajadores migratorios y de 
ser una de las convenciones con más bajas ratificaciones, por no contar que tardó 13 años en entrar en vigor.

En el ínterin, los trabajos en el sistema interamericano de derechos humanos también se terminaron centrando en la figura del "migrante". Con un primer inicio en la Opinión Consultiva nro. 16 de la Corte Interamericana de Derechos Humanos (Corte IDH) referida al derecho a la asistencia consular de los nacionales de un Estado en el exterior, pocos años después la Opinión Consultiva nro. 18 de 2003 volcaba su atención hacia el trabajador migrante. En 1996 comienza a funcionar la Relatoría para trabajadores migratorios y sus familias en la órbita de la Comisión Interamericana de Derechos Humanos (CIDH), predecesora de una Relatoría similar iniciada en el ámbito de Naciones Unidas en 1999. En el mismo año y ámbito se adopta un nuevo comentario general sobre extranjeros ${ }^{4}$. Progresivamente, entonces, toda la atención en derechos humanos es puesta en la "migración" -que supone la extranjería, según las definiciones más aceptada 5 . En el ámbito interamericano, los casos "Velez Loor" (2010), "Nadege Dorzema" (2012), "Pacheco Tineo" (2013), "Personas Dominicanas y Haitianas Expulsadas Vs. República Dominicana" (2014), incluso "Yean y Bosico" (2006), la opinión consultiva sobre niñez migrante (2014), amén de las opiniones consultivas ya mencionadas; también, en el trabajo de la CIDH, con sus informes sobre la detención de migrantes en EEUU (2011), sobre la migración que transita por México (2013), sobre la niñez y la familia en el contexto de la migración en los Estados Unidos (2015) y el más reciente de estándares sobre movilidad humana (2016). La "extranjería" en sí misma, en comparación con la creciente atención que ha recibido la migración, ha tenido poco o ningún desarrollo en derechos humanos y sí, mucha atención (y pocos derechos) desde las medidas antiterroristas adoptadas desde 2001 .

En este marco, el prácticamente desconocido trabajo del Relator apuntó justamente a integrar los principios de derechos humanos como límite a lo que se identifica como el "derecho" de los Estados a expulsar personas extranjeras. En sus palabras, se trata de "cómo conciliar el derecho de expulsar con las exigencias del derecho internacional, en particular las relativas a la protección de los derechos humanos fundamentales", reconociendo posteriormente que frente al "derecho" de los Estados a

sus familiares, Adoptada por la Asamblea General en su resolución 45/158, de 18 de diciembre de 1990.

4. Comité de Derechos Humanos, Observación General nro. 27, Comentarios generales adoptados por el Comité de los Derechos Humanos, “Artículo 12 -La libertad de circulación”, Doc. HRI/GEN/1/Rev. 7 al 202 (1999).

5. Informe de la Relatora Especial sobre los derechos humanos de los migrante, Doc. E/CN.4/2005/85

6. Relator Especial para la Expulsión de Extranjeros, "Informe preliminar sobre la expulsión de los extranjeros presentado por el Sr. Maurice Kamto, Relator Especial”, UN Doc. A/CN.4/554, 4 de abril de 
expulsar y sus prácticas, sólo queda insistir en que "tengan conciencia de la necesidad de preservar los derechos fundamentales y la dignidad de las personas afectadas"”.

Este trabajo se propone, así, sistematizar los diez años de labor y debates. Las producciones que se refieren a ellos son escasas y se concentran en cuestiones muy puntuales como los principios (Martínez, 2013, p. 200-238) o bien, la labor de la relatoría es abordada como un ítem más en las sesiones de la $\mathrm{CDI}^{8}$ con lo cual se licúa su importancia: al margen de que realmente sea un tópico entre los muy variados que aborda la CDI anualmente (reservas de tratados, cláusula de la nación más favorecida, desastres ambientales, etc.), un tratamiento tal no le ha permitido a los autores darle mayor profundidad a la cuestión. Sobre la base de esos trabajos y las fuentes primarias producidas por el Relator, la CDI y de la Asamblea General (principalmente a través del trabajo de la Sexta Comisión) se reconstruye y sistematiza en este artículo el abordaje dado a la cuestión desde su inicio hasta la finalización de sus trabajos en 2014. Indirectamente, también busca dar cuenta de esta intersección del derecho internacional público (en un núcleo puramente de derecho internacional como es la Comisión de Derecho Internacional de Naciones Unidas) y los derechos humanos: más específicamente, como esta perspectiva busca permear los puntos de partida de la soberanía estatal en torno a la extranjería.

\section{CREACIÓN, EXPECTATIVAS E INFORME PRELIMINAR DEL RELATOR (HASTA 2005)}

La primera aparición del tópico es en el año $2000^{9}$, cuando el Grupo de Trabajo sobre el Programa a Largo Plazo recomienda la inclusión del tema. El tema ya había sido propuesto con anterioridad y en 1998, la CDI "toma nota" del informe presentado por el mencionado grupo donde se incluía la posibilidad de tratar el asunto. No será sino hasta 2004 que se

\footnotetext{
2005, párrafo 5.

7. Relator Especial para la Expulsión de Extranjeros, "Segundo informe sobre la expulsión de los extranjeros presentado por el Sr. Maurice Kamto, Relator Especial”, UN Doc. A/CN.4/573, 20 de julio de 2006, párrafo 34

8. Por ejemplo: MATHESON, M., "The Fifty-Fifth Session of the International Law Commission", American Journal of International Law, Vol. 98, No. 2, 2014, pp. 317-324; MURPHY, S., "The Expulsion of Aliens (Revisited) and Other Topics: The Sixty-Sixth Session of the International Law Commission", GW Law School Public Law and Legal Theory, Paper no. 2014-59, 2014, pp. 1-21; RUBIO FERNÁNDEZ, E., "Crónica de Codificación Internacional: la labor de la Comisión de Derecho Internacional", Revista Electrónica de Estudios Internacionales, No. 19, 2010, pp. 1-79; RUBIO FERNÁNDEZ, E., "Crónica de Codificación Internacional: la labor de la Comisión de Derecho Internacional", Revista Electrónica de Estudios Internacionales, No. 28, 2014,pp. 1-41.

9. Ver: Guía analítica para el tópico "Expulsión de extranjeros". Disponible en:
} 
incluye finalmente en el programa, designándose ${ }^{10}$ un relator especial que, que durante los 10 años de trabajo, ostentó el camerunés Maurice Kamto.

Originalmente, el tema había sido propuesto por otro miembro del bloque africano, Emmanuel Addo (Ghana), delineando un breve planteamiento y estructura que eventualmente se podría adoptar ${ }^{11}$. Su punto de partida fue lo que llama el "derecho" de los Estados a expulsar extranjeros: luego de calificarlo como una cuestión "únicamente de derecho interno", reconoce la decisiva influencia del derecho internacional sobre todo para fijar límites: (i) prohibición de expulsar si no hay motivo suficiente para temer por el orden público; (ii) respeto a la norma de no discriminación; (iii) prohibición de abuso de derechos; (iv) extranjeros a los que se haya concedido asilo; (v) expulsiones colectivas o en masa.

Esta perspectiva marcaría el trabajo de los próximos 10 años: lo que interesa, como he mencionado a propósito del informe preliminar, es "cómo conciliar el derecho de expulsar con las exigencias del derecho internacional, en particular las relativas a la protección de los derechos humanos fundamentales"12 una propuesta que recibió el "claro apoyo"13 de los miembros de la CDI, que originalmente se había planteado solamente "examinar cuidadosamente todas las normas sobre el tema existentes ... proceder a su desarrollo normativo y si fuere posible o apropiado, codificarlas para una mejor y más clara aplicación" ${ }^{\text {,14 }}$.

En el debate en 2004 el marco de la Sexta Comisión, sin embargo, quedará en claro que no todos estaban de acuerdo en que la CDI abordara el tema; se objetó la inclusión del tópico por considerarse que "debía ser examinado por otros órganos del sistema de naciones unidas, como la Oficina del Alto Comisionado para los Refugiados (ACNUR) o la Comisión (hoy Consejo) de Derechos Humanos"15 pero más fuertemente, se objetó la pertinencia del trabajo mismo de la CDI (sea

http://legal.un.org/ilc/guide/9_12.htm

10. Comisión de Derecho Internacional, "Informe de la Comisión de Derecho Internacional $56^{\circ}$ período de sesiones ( 3 de mayo a 4 de junio y 5 de julio a 6 de agosto de 2004)", Asamblea General Documentos Oficiales $59^{\circ}$ período de sesiones, $\mathrm{A} / 59 / 10$ de 2004 , párrafo 19

11. Comisión de Derecho Internacional, "Informe sobre la labor realizada en su $52^{\circ}$ período de sesiones $\left(1^{\circ}\right.$ de mayo a 9 de junio y 10 de julio a 18 de agosto de 2000)", Asamblea General, Documentos oficiales $55^{\circ}$ período de sesiones, A/55/10 de 2000. Anexo.

12. Relator Especial para la Expulsión de Extranjeros, "Segundo informe sobre la expulsión de los extranjeros presentado por el Sr. Maurice Kamto, Relator Especial”, UN Doc. A/CN.4/573, 20 de julio de 2006.

13. Comisión de Derecho Internacional, "Informe de la Comisión de Derecho Internacional $57^{\circ}$ período de sesiones (2 de mayo a 3 de junio y 11 de julio a 5 de agosto de 2005)", Asamblea General Documentos Oficiales $60^{\circ}$ período de sesiones, A/60/10 de 2005 , párrafo 251 .

14. Ibídem.

15. Asamblea General, "Informe de la Comisión de Derecho Internacional sobre la labor realizada en su $56^{\circ}$ período de sesiones (2004) Resumen por temas, preparado por la Secretaría, de los debates de la Sexta Comisión de la Asamblea General en su sexagésimo período de sesiones", A/CN.4/549, 31 de enero de 2005, 
por no prestarse a codificación, por ser un tema de negociación política, etc.), una cuestión que será recurrente año tras año hasta incluso bien avanzados los trabajos de la comisión.

En 2005, no obstante, el Relator presenta el informe preliminar; luego de un planteo general con fuentes bibliográficas realmente poco actualizadas (algo que se le criticaría y el Relator defendería como parte de un muestreo histórico de la cuestión), adopta un camino amplísimo para abordar la cuestión: si en el breve planteamiento de 2000 se definía la expulsión como "la orden que da el gobierno de un Estado comunicando a un extranjero o apátrida que abandone el territorio de dicho Estado en un plazo determinado", en este el Relator prefiere comenzar diferenciando todos los tópicos involucrados en la "expulsión", algo que abordará de manera detallada en el siguiente informe. Por lo demás, mantiene su preocupación por los "derechos del expulsado", el régimen para trabajadores migratorios, las expulsiones colectivas, las razones para la expulsión en general y por la intersección entre el derecho de los Estados (que reputa de orden interno) y el derecho internacional, en particular el DIDH ${ }^{16}$ "un contrapeso". (Comisión de Derecho Internacional, Doc. A/60/10 de 2005, citado, párrafo 263)

Este informe preliminar es examinado por la CDI en su $57^{\circ}$ sesión (2005). En su exposición en el debate, una de las preguntas fundamentales del relator es justamente "qué tratamiento había que reservar a las normas existentes que figuraban en varios tratados de derechos humanos" (Comisión de Derecho Internacional, Doc. A/60/10 de 2005, citado, párrafo 263) y manifiesta su preferencia por un "régimen completo...para el proyecto de artículos" (énfasis agregado). Esta cuestión terminará siendo central en los debates. Como explicará uno de sus miembros,

(...) cuando la Comisión completa un proyecto, hay tres importantes decisiones a tomar. Una, la Comisión debe decidir como 'empacar' el producto, si es como 'draft articles', 'draft principles' o en alguna otra manera. Segunda...debe considerar si y cómo caracterizar las reglas sentadas en el proyecto, quizás como codificación de derecho internacional, como desarrollo progresivo o como una combinación de ambas. Finalmente, debe decidir sobre una recomendación a la Asamblea General sobre qué hacer con el proyecto. (Murphy, 2014, p. 4) 
Sin perjuicio de que abordaré estas cuestiones hacia el final, en particular la primera ocupó un lugar considerable en los debates. En el primero, tuvo apoyo la propuesta del Relator de no limitarse a proporcionar una serie de principios supletorios sino una propuesta más integral. (Comisión de Derecho Internacional, Doc. A/60/10 de 2005, pár. 269) No todos estuvieron de acuerdo dentro de la Comisión y el tema volvió a plantearse en los debates de la Sexta Comisión, ya que no habría "evidencia de que el tema mereciera ser abordado de forma independientes ni de que fuera adecuado para la codificación y el desarrollo progresivo". (Asamblea General, 2005) ${ }^{17}$

Otro tema de discusión fue la delimitación, una preocupación que surgió tanto en la CDI como en la Sexta Comisión (Asamblea General, 2005, pár. 132) y se propusieron exclusiones: devolución, no admisión de solicitantes de asilo o denegación de entrada. (Asamblea General, 2005, pár. 255) Otra objeción respecto al alcance del tema se planteó al considerar que "todo intento de examinar cuestiones relativas a las políticas de inmigración o emigración afectaría desfavorablemente a las perspectivas de los trabajos de la Comisión" y que en su caso, debería distinguirse claramente entre los extranjeros que se encontraban legalmente en el país de aquellos que se hallaban en situación irregular. (Asamblea General, 2005, pár. 253-254)

Finalmente, hubo dudas sobre el requisito de expresar motivos para la expulsión incluido por el Relator, ya que "no era evidente que...el soberano territorial tuviese originariamente la obligación de invocar una causa de justificación”. (Asamblea General, 2005, pár. 264) Más aún, se plantea en la CDI que el valor asignado al "derecho" del Estado a expulsar era muy "apriorístico", por la relativización de los estándares en derechos humanos y que no había motivos para que ese derecho fuera tan categórico como se planteaba en el informe. (Asamblea General, 2005, pár. 262). Estas posturas incluso diametralmente opuestas caracterizarían los debates de los siguientes años.

\section{MEMORÁNDUM, SEGUNDO AL CUARTO INFORMES DEL RELATOR Y DEBATES (2006-2008)}

\subsection{El memorándum}

En la sesión de 2005, el relator pide a la Secretaría que elabore una recopilación de los instrumentos, la doctrina y la jurisprudencia sobre la 
expulsión de extranjeros. El trabajo resultante (Comisión de Derecho Internacional, UN/Doc. A/CN.4/565, 2006) excedería en mucho la solicitud; no sólo por sus más de 600 páginas, sino porque es realmente un "análisis completo", tal las palabras de la Secretaría, de todos los aspectos que podrían estar involucrados. Entre los que son relevantes desde el punto de vista de los derechos humanos, aborda la diferencia entre presencia "legítima" y "física" de un extranjero (parte III.B), la interceptación de extranjeros, en particular en alta mar (III.4), las limitaciones generales al "derecho" de un Estado a expulsar (VI), los motivos para la expulsión y otras consideraciones, como la unidad familiar y el destino (VII), requisitos procesales (VIII) y ejecución de la decisión de expulsión (IX), un apartado especial para extranjeros "ilegales" (X.A), residentes (X.B), trabajadores migratorios (X.C), "menores de edad" (X.D), etc., y finalmente, una sección sobre la expulsión colectiva y en masa (XII).

Sería imposible presentar aquí este exhaustivo trabajo hecho por la Secretaría pero a grandes rasgos, puede mencionarse que lo que luego será proyecto final del Relator refleja buena parte de los temas abordados en el memorándum. Por ejemplo, una inquietud en este memo es si habría que limitar el análisis a los extranjeros presentes legalmente en el territorio, a la que se inclina por la negativa dada la importancia práctica que tiene, precisamente, esa cuestión (Comisión de Derecho Internacional, UN/Doc. A/CN.4/565, 2006, pár. 50); ello sería ratificado por el Relator en su Segundo Informe. Así, por ejemplo, dirá que "al parecer" tanto las limitaciones que se identifican como tradicionales (buena fe, prohibición de arbitrariedad y de abuso del derecho) (Comisión de Derecho Internacional, UN/Doc. A/CN.4/565, 2006, pár. 201-298) como las contemporáneas (principio de no discriminación, principio de legalidad) (Comisión de Derecho Internacional, UN/Doc. A/CN.4/565, 2006, pár. 256-294) también se aplican a ellos; igualmente, la necesidad de que existan motivos válidos fijados en la ley (Comisión de Derecho Internacional, UN/Doc. A/CN.4/565, 2006, pár. 748) y algunas consideraciones de derechos humanos: protección por ser personas sometidas a la jurisdicción de un Estado y expulsión acorde a la ley, extendiendo la protección del PIDCyP que sólo la reconoce para aquellos extranjeros en situación legal.

A los efectos de este trabajo, también es pertinente dar cuenta del lugar que el Memorándum asigna a las normas en derechos humanos: menciona que estas han tenido un "efecto importante" sobre las normas de derecho internacional que regulan el trato a extranjeros "en la medida en que se reconoce que esos derechos corresponden a las personas en tanto seres humanos independientemente de su condición de nacionales 
o extranjeros en relación con un Estado determinado" (Comisión de Derecho Internacional, UN/Doc. A/CN.4/565, 2006, pár. 251) aunque acto seguido reconoce que aquellas normas brindan una insuficiente protección en materia de expulsión. Algunas reglas protectoras, enumera, se encuentran relacionadas "a la determinación de la licitud de una expulsión, como los derechos de la familia, los derechos del niño, la libertad de expresión, los derechos sindicales, el derecho de propiedad, el derecho a ingresar o regresar al Estado de la nacionalidad de la persona, las garantías procesales, el derecho a un tratamiento humano", (Comisión de Derecho Internacional, UN/Doc. A/CN.4/565, 2006, pár. 253) temas que serán incluidos particularmente en el Memorándum, por ejemplo: familia ${ }^{18}$, niños $/ \mathrm{as}^{19}$, etc.

Por último, el principio de no discriminación es presentado en un doble nivel: como un principio de "derecho internacional tradicional" ${ }^{20} \mathrm{y}$ de derechos humanos ${ }^{21}$. Esta presentación obedece a que consideran que, dado que los nacionales no pueden ser expulsados, el principio de no discriminación no sería pertinente y sólo regiría con respecto a los derechos protegidos por el tratado de que se trate: vida, propiedad, etc. El argumento no deja de ser interesante y la jurisprudencia internacional citada en los párrafos siguientes del memo refuerza la idea, que retomaré hacia el final.

\subsection{Segundo y tercer informes del relator (2007)}

En su $58^{\circ}$ sesión, la CDI decide no considerar el segundo informe del relator (que en lugar de presentarse en los primeros meses del año, se presentó en julio) y diferir la cuestión para la siguiente, algo que resultó en un lamento por parte de la Sexta Comisión ${ }^{22}$. En la sesión $59^{\circ}$ de 2007 , entonces, se consideran ambos documentos.

En el segundo informe ${ }^{23}$ el Relator esboza algunas respuestas a los comentarios y objeciones surgidos en el debate alrededor del informe preliminar, particularmente en torno a aquellas propuestas planteadas dentro de la Sexta Comisión sobre el alcance del tema. Dedica entonces

párrafo 129.

18. Ver: Comisión de Derecho Internacional, UN/Doc. A/CN.4/565, 2006, párrafos 446-467; 805-806; 932.

19. Ver: Comisión de Derecho Internacional, UN/Doc. A/CN.4/565, 2006, párrafos 468-474; 826-833.

20. Ver: Comisión de Derecho Internacional, UN/Doc. A/CN.4/565, 2006, , párrafos 256-286.

21. Ver: Comisión de Derecho Internacional, UN/Doc. A/CN.4/565, 2006, párrafo 482.

22. Asamblea General, "Informe de la Comisión de Derecho Internacional sobre la labor realizada en su $58^{\circ}$ período de sesiones (2006) Resumen por temas, preparado por la Secretaría, de los debates de la Sexta Comisión de la Asamblea General en su sexagésimo período de sesiones", A/CN.4/577, 19 de enero de 2007, párrafo 100.

23. Relator Especial para la Expulsión de Extranjeros, "Segundo informe sobre la expulsión de los extranjeros presentado por el Sr. Maurice Kamto, Relator Especial”, UN Doc. A/CN.4/573, 20 de julio de 
buena parte del informe a algunas consideraciones generales de lo que sería la competencia personal del proyecto: extranjeros regulares, irregulares, refugiados, apátridas, etc., para luego hacer lo propio con la competencia material: qué es una expulsión ${ }^{24}$ comparándola con otras instituciones (deportación, extradición, etc.) y apuntando algunos conceptos sobre la competencia espacial (territorio, frontera). Como conclusión, presenta propuestas de artículos $1^{25}$ y $2^{26}$.

A modo de actualización, aborda dos temas: el impacto de las medidas antiterroristas en el trato a extranjeros y la inmigración irregular. En ambos casos, emplea como ejemplos las draconianas medidas adoptadas en Francia, vía la desnacionalización para expulsar (Relator Especial para la Expulsión de Extranjeros, UN Doc. A/CN.4/573, 2006, pár. 18) y el llamado general a aumentar las cuotas de personas devueltas. Será justamente a propósito de estos casos donde el Relator toma posición en el tema en estudio: "la eficacia de estas medidas es dudosa..." y aparta "la mirada de las causas profundas de la inmigración clandestina que son el desequilibrio económico del mundo y la pobreza extrema en los países de origen de los inmigrantes ilegales". (Relator Especial para la Expulsión de Extranjeros, UN Doc. A/CN.4/573, 2006, pár. 21) Así, señalará que "la inmigración irregular es uno de los hechos dramáticos que revelan los desequilibrios socioeconómicos agravados por la globalización de la economía y la pauperización galopante de los países subdesarrollados". (Relator Especial para la Expulsión de Extranjeros, UN Doc. A/CN.4/573, 2006, pár. 30)

En su tercer informe ${ }^{27}$ se dedica a examinar los principios generales del derecho internacional por los que se rige la expulsión de extranjeros. El

2006.

24. Relator Especial para la Expulsión de Extranjeros, "Segundo informe sobre la expulsión de los extranjeros presentado por el Sr. Maurice Kamto, Relator Especial”, UN Doc. A/CN.4/573, 20 de julio de 2006, párrafo 153 .

25. "Artículo 1: Ámbito de aplicación. 1) El presente proyecto de artículos se aplica a toda persona que se encuentra en un Estado del que no es nacional; 2) Se aplica en particular a los extranjeros en situación regular o irregular en el Estado de acogida, a los refugiados, asilados, apátridas, trabajadores migratorios, nacionales de un Estado enemigo, y nacionales del Estado que lo expulsa y que han perdido su nacionalidad o han sido despojados de ella". Esta redacción es la que sería enviada finalmente al Comité de Redacción (Doc. A/CN.4/642 de 2011); en el proyecto aprobado en primera lectura, se incluiría la exclusión del personal diplomático y consular.

26. “Artículo 2: Definiciones. A los efectos del presente proyecto de artículos: 1) Se entiende por expulsión de un extranjero el acto o el comportamiento en virtud del cual un Estado que expulsa obliga a un natural de otro Estado a abandonar su territorio. 2) Se entiende por: a) Extranjero, un natural de un Estado distinto del Estado territorial o Estado que expulsa; b) Expulsión, un acto o un comportamiento en virtud de cual el Estado que expulsa obliga al extranjero a abandonar su territorio; c) Frontera, la zona limítrofe del territorio del Estado que expulsa en la cual el extranjero no goza de los beneficios que otorga el estatuto del residente y fuera de la cual termina el procedimiento nacional de expulsión; d) Natural, toda persona que, en virtud de un vínculo jurídico cualquiera, incluida la nacionalidad, queda comprendido dentro [de la jurisdicción] [de la competencia personal] de un Estado; e) Territorio, el espacio dentro del cual el Estado ejerce el conjunto de competencias que dimanan de su soberanía"; luego se suprimirían las referencias a "frontera" y "territorio". 27. Relator Especial para la Expulsión de Extranjeros, "Tercer informe sobre la expulsión de extranjeros 
primero que aborda es el controvertido "derecho" a expulsar que tienen los Estados, una facultad de orden interno que sólo encontraría límites en algunos principios "intrínsecos" de derecho internacional, entre ellos, el pacta sunt servanda, el de buena fe y la obligación de respetar el ius cogens. De allí el tercer artículo que se propone para el proyecto. ${ }^{28}$

A continuación menciona principios específicos no ya del derecho internacional, sino del acto de expulsión: (i) los relacionados con las personas objeto de expulsión (ratione personae), (ii) los relativos a los derechos fundamentales de estas personas (ratione materiae) y (iii) los que tienen que ver con el procedimiento que ha de seguirse ratione prosequi). (Doc. A/CN.4/581 de 2007, pár. 27) La primera cuestión será tratada en el tercer y cuarto informe mientras que las segunda y tercera, en el quinto y sexto.

Con relación al ámbito de aplicación personal se sistematizan varias prohibiciones recogidas de diversos tratados y documentos vigentes: la de expulsar a un nacional, lo que da lugar a un minucioso análisis y propuesta de artículo consecuente ${ }^{29}$, la de expulsar a un refugiado con la sola excepción de razones de seguridad u orden público y su propuesta de artículo $^{30}$, la de expulsar a una persona apátrida ${ }^{31}$, la de expulsiones

Presentado por el Sr. Maurice Kamto, Relator Especial", UN Doc. A/CN.4/581, 19 de abril de 2007.

28. "Art. 3. 1. Un Estado tiene el derecho de expulsar a un extranjero de su territorio. 2. Sin embargo, la expulsión deberá llevarse a cabo respetando los principios fundamentales del derecho internacional. En particular, el Estado debe actuar de buena fe y respetando sus obligaciones internacionales". Esta redacción es la que sería enviada finalmente al Comité de Redacción; en el proyecto aprobado en primera lectura, se referiría al respeto al proyecto de artículos y a los derechos humanos.

29. Proyecto de artículo 4: "No expulsión por un Estado de sus propios nacionales. 1. Un Estado no podrá expulsar a sus propios nacionales. 2. No obstante, si por motivos excepcionales debe proceder a tal expulsión, sólo podrá llevarla a cabo con el consentimiento de un Estado de acogida. 3. Una persona expulsada de su propio país tendrá derecho a regresar a él en todo momento a petición del Estado de acogida". El proyecto original de artículo 4, que era sobre motivos de expulsión, pasará a ser el artículo 9 en el informe del Relator de 2011. Este artículo 4 era en los primeros informes el artículo 5; esta redacción es la que sería enviada finalmente al Comité de Redacción (Doc. A/CN.4/642 de 2011).

30. Proyecto de artículo 5. No expulsión de refugiados. 1. Un Estado no podrá expulsar a refugiado alguno que se halle legalmente en el territorio de tal Estado, a no ser por razones de seguridad nacional, de orden público [o de terrorismo], o si el interesado, habiendo sido objeto de una condena definitiva por un delito particularmente grave, constituye una amenaza para la comunidad de tal Estado. 2. Las disposiciones del párrafo 1 del presente artículo se aplicarán igualmente a cualquier persona que se halle ilegalmente en el territorio del Estado de acogida y haya solicitado el estatuto de refugiado, salvo que sea manifiesto que el único objetivo de esta solicitud es evitar cualquier medida de expulsión que pueda adoptarse contra ella [contra esa persona]. Esta redacción es la que sería enviada finalmente al Comité de Redacción, aunque como artículo 6 (Doc. A/CN.4/642, citado, 2011). en la aprobación en primera lectura se incorporará un último párrafo con el principio de no devolución.

31. La propuesta, que en la versión castellana se lee como "artículo 5. No expulsión de refugiados", cuando debería decir "apátridas", dice: 1 . Un Estado no podrá expulsar a apátrida alguno que se halle [legalmente] en el territorio de tal Estado, a no ser por razones de seguridad nacional, de orden público [o de terrorismo], o si el interesado, habiendo sido objeto de una condena definitiva por un delito particularmente grave, constituye una amenaza para la comunidad de tal Estado. el presente proyecto de artículos le concederá un plazo razonable dentro del cual pueda gestionar su admisión legal en otro país. [No obstante, si transcurrido ese plazo el apátrida no ha logrado ser admitido en ningún país de acogida, el Estado podrá [, con el consentimiento del apátrida,] expulsarlo a cualquier Estado que acepte acogerlo.] Esta redacción es la que sería enviada finalmente al Comité de Redacción, aunque como artículo 7 (Informe Relator 2011); en la 
colectivas o en masa, analizando la cuestión tanto en tiempos de paz como de conflicto armado (como sería el llamado "intercambio de poblaciones"), preguntándose si la distinción sigue siendo justificada (Doc. A/CN.4/581 de 2007, pár. 132-133) y dando finalmente una propuesta de artículo al respecto ${ }^{32}$. Esta cuestión será retomada en el 6 to. Informe.

En el examen de ambos informes en la CDI, se decidió enviar las propuestas de artículos 1 al 7 al Comité de Redacción (Asamblea General Documentos Oficiales, A/62/10 de 2007, pár. 188) ${ }^{33}$ con mínimas modificaciones, previa discusión punto por punto de las propuesta: aunque no aportan mayormente al propósito de este artículo (como la reiterada cuestión sobre la pertinencia de que la Comisión se ocupe del tema) sí existen algunas relevantes como la propuesta de incluir en el proyecto de artículos una disposición dedicada a los trabajadores migratorios y sus familiares, tomando como base el artículo 22 de la CTM y se sugirió que la Comisión examinara los posibles motivos de ilegalidad de una expulsión. (Asamblea General Documentos Oficiales, A/62/10 de 2007, pár. 246247)

Por su parte, en el examen por la Sexta Comisión, volvieron a surgir las cuestiones acerca del packaging, esto es, si se trataría de un borrador de artículos o más bien, un conjunto de principios ${ }^{34}$. Las demás cuestiones debatidas son análogas a las del debate en la CDI.

\subsection{Cuarto informe y reportes del Comité de Redacción (2008)}

El cuarto informe complementa el tópico sobre la competencia personal $\mathrm{y}$ al mismo tiempo funciona como un paréntesis entre el tercer y quinto informes, al abordar dos cuestiones que habían suscitado particular

aprobación en primera lectura se adoptaría una versión mucho más simplificada.

32. Proyecto de artículo 7: "No expulsión colectiva. 1. Se prohíbe la expulsión colectiva de extranjeros, incluidos los trabajadores migratorios y sus familiares. Sin embargo, un Estado podrá expulsar simultáneamente a los miembros de un grupo de extranjeros siempre que la medida de expulsión se adopte al término y sobre la base de un examen razonable y objetivo de la situación particular de cada uno de los extranjeros que integran el grupo. 2. Se entiende por expulsión colectiva todo acto o comportamiento por el cual un Estado obliga a un grupo de extranjeros a abandonar su territorio. 3. No podrán adoptarse medidas de expulsión colectiva contra los extranjeros nacionales de un Estado inmerso en un conflicto armado, salvo que se muestren hostiles, como grupo, hacia el Estado de acogida. Esta redacción es la que sería enviada finalmente al Comité de Redacción, aunque como artículo 8 (Doc. A/CN.4/642, citado, 2011).

33. Comisión de Derecho Internacional, "Informe de la Comisión de Derecho Internacional $59^{\circ}$ período de sesiones (7 de mayo a 5 de junio y 9 de julio a 10 de agosto de 2007)". Asamblea General Documentos Oficiales $62^{\circ}$ período de sesiones, A/62/10 de 2007, párrafo 188.

34. Asamblea General, "Informe de la Comisión de Derecho Internacional sobre la labor realizada en su $59^{\circ}$ período de sesiones (2007) Resumen por temas, preparado por la Secretaría, de los debates de la Sexta Comisión de la Asamblea General en su sexagésimo período de sesiones", A/CN.4/588, 24 de enero de 2008 , 
interés y que terminarían encendiendo acalorados debates durante las sesiones de 2008: la situación de las personas con doble nacionalidad y la pérdida de la nacionalidad y la desnacionalización ${ }^{35}$.

En pos de clarificar el artículo propuesto que prohíbe expulsar a los nacionales, el Relator aclara que no incluye a aquellas personas que tienen doble o múltiple nacionalidad, con lo que la prohibición de expulsión sería sólo para quienes tienen una nacionalidad: la del Estado que expulsa. Incluso, el Relator dudó de que se incluyeran estas consideraciones en un proyecto de artículo sobre expulsión ${ }^{36} \mathrm{y}$ a todo evento, dejó en claro que "no estaba dispuesto para emprender un estudio de las cuestiones relativas al régimen de la nacionalidad". (Asamblea General Documentos Oficiales $63^{\circ}$ período de sesiones, A/63/10 de 2008, párrafo 207).

A partir de la consideración de las cuestiones planteadas en el 4to. Informe y del debate sobre si convenía o no incluir la cuestión en un proyecto de artículos, la CDI decide (en su última sesión de debate en pleno) formar un grupo de trabajo para examinar las cuestiones que planteaba la expulsión de personas con doble nacionalidad o nacionalidad múltiple y la privación de la nacionalidad en relación con la expulsión. (Asamblea General Documentos Oficiales $63^{\circ}$ período de sesiones, A/63/10 de 2008, pár. 170-190). Poco después, este Grupo concluiría que los Estados tampoco podrían expulsar a las personas que tuvieran, además, otra/s nacionalidad/es, criterio que sería recogido en los debates al interior de la Sexta Comisión, desde donde se ratificará la opinión de que expulsar a nacionales también incluía a quienes habían adquirido una o más nacionalidades distintas.

En esta $60^{\circ}$ sesión también se presenta oralmente el reporte del Comité de Redacción (Comisión de Derecho Internacional, Doc. A/63/10 de 2008, pár. 172) y se decide que los siete proyectos de artículos remitidos para su redacción "permaneciesen en su marco hasta que se hubieran

párrafo 95

35. Una de las posibles relaciones entre ambas cuestiones queda clara en los primeros párrafos: muchos Estados recurren a la desnacionalización de una persona con doble nacionalidad para evitar planteos jurídicos del otro Estado, aunque se reconoce que "los casos de expulsión de binacionales sin una desnacionalización previa por parte del Estado que los expulsa no son raros en la práctica” (Relator Especial para la Expulsión de Extranjeros, "Cuarto informe sobre la expulsión de extranjeros Presentado por el Sr. Maurice Kamto, Relator Especial”, A/CN.4/594, 24 de marzo de 2008, párrafo 10).

36. Comisión de Derecho Internacional, "Informe de la Comisión de Derecho Internacional $60^{\circ}$ período de sesiones ( 5 de mayo a 6 de junio y 7 de julio a 8 de agosto de 2008)". Asamblea General Documentos Oficiales $63^{\circ}$ período de sesiones, $\mathrm{A} / 63 / 10$ de 2008 , párrafo 182 .

37. Asamblea General, "Informe de la Comisión de Derecho Internacional sobre la labor realizada en su $61^{\circ}$ período de sesiones (2009) Resumen por temas, preparado por la Secretaría, de los debates de la Sexta Comisión de la Asamblea General en su sexagésimo período de sesiones", A/CN.4/620, 26 de enero de 2010, párrafo 30. El proyecto aprobado en primera lectura incluyó finalmente una disposición sobre privación de la 
aprobado provisionalmente todos los proyectos de artículos". (Rubio, 2010, p. 53) Al año siguiente y en el marco de la $61^{\circ}$ sesión, el Relator presenta el quinto informe, que es específico de derechos humanos y al que dedicaré mayor atención.

\section{QU IN T O I N F O RME, DEBATE EN LA C D I Y REFORMULACIÓN (2009)}

En el quinto informe se estudian más en detalle los derechos planteados como límites a la expulsión, retomando así la serie de limitaciones a la facultad estatal de expulsión referida en el tercer informe; en los debates, también se incluyó la primera de las tres series de observaciones (hechas en 2009, 2010 y 2014) formuladas por los Estados. Respondiendo de alguna manera a las críticas sobre la deficiente atención a las normas de derechos humanos, hechas a propósito del informe anterior (Comisión de Derecho Internacional, Doc. A/63/10 de 2008, citado, párrafo 185) el punto de partida del quinto informe es puramente de derechos humanos:

(...) toda persona sujeta a una expulsión, cualesquiera que sean los motivos, es un ser humano que, como tal, debe seguir disfrutando de todos sus derechos fundamentales. Esa persona goza de los mismos atributos y aspira a las mismas libertades con independencia de su raza, etnia, sexo, creencias o nacionalidad. (Relator Especial para la Expulsión de Extranjeros, A/CN.4/611, 2009, pár. 10)

Por si hubiera dudas, apunta también que "la condición de extranjero no coloca a la persona en una situación de inferioridad en relación con la protección que confieren los derechos humanos" (Relator Especial para la Expulsión de Extranjeros, A/CN.4/611, 2009, pár. 14) e incluso, que "es tanto más necesario proteger a la persona que un Estado ha decidido expulsar cuanto que dicha persona es vulnerable por su condición de extranjera y por la perspectiva de su expulsión". (Relator Especial para la Expulsión de Extranjeros, A/CN.4/611, 2009, pár. 10)

Ahora bien, el Relator opina que es poco realista proponer que la persona en vías de expulsión goce de todos los derechos (a la educación, a trabajar, etc.) pero que sí debería gozar de "derechos fundamentales". (Relator Especial para la Expulsión de Extranjeros,, A/CN.4/611, 2009, pár. 17) Luego de reconocer que no hay acuerdo sobre lo que estos significan, decide referirse a ellos como "núcleo duro" como sinónimo de "derechos fundamentales" para referir aquellos derechos que no 
admiten ninguna excepción. (Relator Especial para la Expulsión de Extranjeros, A/CN.4/611, 2009, pár. 28-29)

En los debates hubo nuevamente posturas encontradas: desde aquellas que cuestionaban la tarea misma del contenido obligacional, (Relator Especial para la Expulsión de Extranjeros, A/CN.4/611, 2009, pár. 104) la enumeración de la lista de derechos, la conveniencia de no listar sino mencionar de manera general o ampliar la lista. (Relator Especial para la Expulsión de Extranjeros,,A/CN.4/611, 2009, pár. 106-108). Sobre este núcleo duro no se hace un artículo específico sino que queda subsumido en el artículo $8^{39}$ y luego, en derechos particulares. En los debates en la CDI, algunos miembros se mostraron de acuerdo y otros plantearon que era muy limitado; se propuso suprimir la referencia a los "derechos fundamentales" y a los derechos "que vengan impuestos por [la] condición específica [de la persona expulsada]", y reformular el proyecto de artículo 8 de manera que se estableciera la obligación del Estado autor de la expulsión de respetar todos los derechos humanos aplicables a una persona amenazada de expulsión, tanto en virtud de los instrumentos convencionales vinculantes para el Estado autor de la expulsión como en virtud del derecho internacional consuetudinario. (Relator Especial para la Expulsión de Extranjeros,,A/CN.4/611, 2009, pár. 111)

Finalmente, el texto fue modificado por el Relator y se sustituyó la referencia a "derechos fundamentales" por la de "derechos humanos" (Rubio, 2010, p. 54) quedando redactado de la siguiente manera: "toda persona expulsada o en vías de expulsión tiene derecho a que se respeten sus derechos humanos, en particular los enunciados en el presente proyecto de artículos ${ }^{\text {,40 }}$. No obstante, esta nueva redacción no sería debatida en Comisión hasta la sesión siguiente.

nacionalidad (artículo 9).

38. Para salvar todas las posibles listas de contenido del "núcleo duro", adopta la propuesta del profesor Sudre de identificar un núcleo duro de estos núcleos duros, que serían el derecho a la vida, el derecho a no sufrir torturas ni tratos inhumanos o degradantes, el derecho a no ser sometido a esclavitud ni servidumbre y el derecho a la no retroactividad de la ley penal, (p. 42) a los cuales agrega el principio de no discriminación, el derecho al respeto de la integridad física de la persona en vías de expulsión, el derecho al respeto de la vida familiar y el derecho de toda persona a no ser expulsada a un país en que peligre su vida (p. 43); a la dignidad, a la no discriminación, a la integridad, a la vida familiar (p. 52).

39. Luego de recordar el tipo de obligaciones (erga omnes) que se imponen a los Estados en materia de derechos humano, el Relator propone el siguiente artículo: "Proyecto de artículo 8: Obligación general de respetar los derechos humanos de la persona en vías de expulsión. Toda persona expulsada o en vías de expulsión tendrá derecho a que se respeten sus derechos fundamentales y todos los demás derechos que vengan impuestos por su condición específica". Este artículo será, en el Sexto Informe, el proyecto de artículo B (fusionando artículos 8 y 10); en la versión final enviada al comité de redacción, esta disposición no se verá reflejada.

40. Relator Especial para la Expulsión de Extranjeros, "Expulsión de Extranjeros. Proyectos de artículo sobre la protección de los derechos humanos de la persona expulsada o en vías de expulsión, reordenados por el Relator Especial, Sr. Maurice Kamto, a la luz del debate celebrado en sesión plenaria durante la primera 
Sobre el núcleo duro, decía, se desgranan algunos derechos particulares: a la vida (proyecto de artículo 9) ${ }^{41}$, a la dignidad (artículo 10) ${ }^{42}$, prohibición de la tortura y de las penas o tratos crueles, inhumanos o degradantes (artículo 11) ${ }^{43}$. Esta última propuesta recibió dos grandes críticas en el debate en la CDI: la primera, que el Relator no hubiera tenido en cuenta la definición dada por el estatuto de la CPI (Asamblea General Documentos Oficiales, A/64/10, pár. 121) ${ }^{44}$ y que reemplazara la referencia a "riesgo grave" por "riesgo real" (Asamblea General Documentos Oficiales, A/64/10, pár. 124).

A continuación se ocupa específicamente de la situación de la infancia, citando jurisprudencia que reconoce que la vulnerabilidad de los niños prevalece sobre su situación administrativa y que deben ser tratados como tales, con independencia del carácter de su estancia en el país de que se trate. "No obstante", dice, "no hay ningún elemento que permita afirmar... que el enunciado de esa conclusión exprese, a fecha de hoy, una norma de derecho consuetudinario" sino que se trataría de una "tendencia en la materia". En los debates, se sugirió además que se enunciara que en todos los casos de expulsión en que intervinieran niños debía prevalecer el interés superior del niño, (Asamblea General, Doc. A/64/10, citado, párrafo 126) postura con la que el Relator, por supuesto, estuvo de acuerdo y así, se propuso reformular el párrafo 2 de forma que

parte del presente período de sesiones”, A/CN.4/617,21 de julio de 2009, página 2 (énfasis en el original).

41. Proyecto de artículo 9. Este pasará finalmente al Comité de Redacción como artículo 14 y con una nueva redacción: "1. E1 Estado autor de la expulsión protegerá el derecho a la vida de la persona expulsada o en vías de expulsión. 2. Un Estado no podrá someter a una persona expulsada o en vías de expulsión a tortura ni a tratos crueles, inhumanos o degradantes en su territorio o en un territorio bajo su jurisdicción", suprimiendo así la referencia a la pena de muerte (Doc. A/CN.4/617). Para el Estado de destino, se redactaría un artículo similar, que sería el artículo 18 del proyecto final enviado al Comité de Redacción en 2011 y se regularían de manera separada la vida y la tortura (arts. 17 y 18 para el Estado que expulsa y 23 y 24 para el de destino, en la aprobación en primera lectura).

42. Proyecto de artículo 10: Obligación de respetar la dignidad de la persona en vías de expulsión. 1. La dignidad humana es inviolable. 2. La dignidad de una persona en vías de expulsión será respetada y protegida en cualquier circunstancia, con independencia de que la persona se encuentre en situación legal o ilegal en el Estado que la expulsa". En la redacción posterior dada en el mismo período de sesiones (Doc. A/CN.4/617), se suprime el párrafo 1 y la referencia a la situación legal o ilegal. No obstante, esta modificación no sería examinada hasta el siguiente período de sesiones; en la aprobación en primera lectura tendrá una formulación similar.

43. Proyecto de artículo 11. Este artículo sería subsumido en el artículo referido al derecho a la vida; se redactaría una disposición similar para el Estado de destino, que será el proyecto de artículo 19 (Doc. A/CN.4/642, citado, 2011).

44. Comisión de Derecho Internacional, "Informe de la Comisión de Derecho Internacional $61^{\circ}$ período de sesiones (4 de mayo a 5 de junio y 6 de julio a 7 de agosto de 2009)". Asamblea General Documentos Oficiales $63^{\circ}$ período de sesiones, $\mathrm{A} / 64 / 10$, párrafo 121 .

45. Asamblea General Documentos Oficiales $63^{\circ}$ período de sesiones, A/64/10, párrafo 125. "Proyecto de artículo 12: Caso específico de la protección del niño en vías de expulsión. 1. El niño en vías de expulsión deberá ser considerado, tratado y protegido como tal, con independencia del carácter de su estancia en el país. 2. Constituirán tratos crueles, inhumanos y degradantes, en especial en el caso de los niños, el hecho de permanecer detenido en las mismas condiciones que un adulto o por un plazo prolongado. 3. La definición de niño a los efectos del presente artículo corresponderá a la contemplada en el artículo 1 de la Convención sobre los Derechos del Niño, de 20 de noviembre de 1989”. Este artículo pasará finalmente al Comité de Redacción como artículo 13, con la redacción del "caso específico de las personas vulnerables", que se reproduce unas 
se indicara que, en algunos casos, el interés superior del niño podría exigir que este no fuera separado de los adultos con motivo de una detención con miras a su expulsión. Asimismo, algunos miembros sugirieron que se contemplara una protección específica para otras categorías de personas vulnerables, como las personas de edad, las personas con discapacidad física o mental o las mujeres, y muy especialmente las mujeres embarazadas (Asamblea General, Doc. A/64/10, citado, párrafo 127).

El informe se completa con propuestas referidas a la familia ${ }^{46}$ y a la no discriminación ${ }^{47}$. Sobre la familia, en los debates se propuso agregar, por ejemplo, un párrafo que estableciera, previo a la expulsión, que "un Estado debería tener en cuenta los vínculos familiares que esa persona tuviera con personas residentes en el territorio del Estado autor de la expulsión, así como el período durante el cual el extranjero había residido en dicho territorio" (Asamblea General, Doc. A/64/10, pár. 129) receptando así una de las principales tendencias en protección legal de derechos humanos.

Sobre la no discriminación, en los debates se sugirió que su ubicación en el proyecto de artículos fuera anterior, por ejemplo a continuación del artículo 8 propuesto, habida cuenta del carácter general del principio. Otros miembros hicieron notar que la obligación de no discriminación se aplicaba sólo entre extranjeros y no entre nacionales del Estado que expulsaba y extranjeros (Rubio, 2010, p. 55). Frente a estos planteos, el Relator sostuvo que "en el contexto de la expulsión, existía un principio autónomo que prohibía a los Estados proceder a la discriminación entre extranjeros". Asimismo, varios propusieron ampliar la lista de motivos de discriminación prohibidos a fin de incluir, en particular, la edad, la discapacidad o la orientación sexual, petición que finalmente no fue acogida por el Relator (Rubio, 2010, p. 55).

\footnotetext{
notas más adelante.

46. Proyecto de artículo 13: "Obligación de respetar el derecho a la vida privada y a la vida familiar. 1. E Estado que expulsa respetará el derecho a la vida privada y a la vida familiar de la persona en vías de expulsión. 2. Dicho Estado sólo podrá dejar sin efecto el derecho contemplado en el párrafo 1 del presente artículo en los casos previstos por la ley y con observancia de un justo equilibrio entre los intereses del Estado y los de la persona en cuestión”. En la reordenación de artículos (A/CN.4/617) quedará como artículo 12; se reemplaza la referencia a "ley" por "derecho internacional", amén del agregado "persona expulsada", junto a "persona en vías de expulsión”. Esta nueva propuesta no sería examinada por la Comisión hasta el próximo período de sesiones. Finalmente pasará al Comité de Redacción como artículo 15 Doc. A/CN.4/642, citado, 2011; artículo 20 de la aprobación en primera lectura.

47. Proyecto de artículo 14: "Obligación de no discriminar 1. El Estado ejercerá su derecho de expulsión sin discriminar a las personas afectadas, en particular por motivos de raza, color, sexo, idioma, religión, opinión política o de otra índole, origen nacional o social, patrimonio, nacimiento o cualquier otra condición. 2. La no discriminación se aplicará asimismo al disfrute por la persona en vías de expulsión de los derechos y libertades previstos tanto en las normas internacionales de derechos humanos como en la legislación del Estado que expulsa”. Este artículo pasará finalmente al Comité de Redacción como artículo 12, con la adición hecha en la revisión de 2009: "la no discriminación se aplicará asimismo, entre las personas expulsadas o en
} 
Frente a estas propuestas, el Relator inicia una reordenación y clarificación (Relator Especial para la Expulsión de Extranjeros, Doc. A/CN.4/617, 2009), citado de los artículos propuestos en su quinto informe, muchos de los cuales ya he mencionado con anterioridad. Para el caso particular de la obligación de no discriminar, este artículo 14 original se mueve al lugar décimo y el segundo párrafo se agrega la referencia a "persona expulsada"48. Se agrega también el "caso específico de las personas vulnerables", donde se incluyen (dentro del artículo que refería a niños/as) personas de edad y mujeres embarazadas. También se amplía el artículo referido al derecho a la vida, incluyendo en la reformulación una "protección contra los riesgos de violación de los derechos humanos en el Estado de destino", en dos artículos: (i) la "obligación de garantizar el respeto del derecho a la vida y a la libertad individual de la persona expulsada o en vías de expulsión en el Estado de destino" de expulsión contra la tortura y los tratos crueles, inhumanos o degradantes en el Estado de destino",50. Amén del Estado de destino, se incluye una cláusula para el Estado de tránsito que, aunque sin disposiciones específicas, fue agregada por el Relator, muy atinadamente, para "completar el dispositivo de protección de los derechos de la persona expulsada durante todo el proceso y a lo largo de todo el recorrido desde el Estado autor de la expulsión hasta el Estado de destino".

Por último, en los debates en la Sexta Comisión se expresó la opinión de que

(...) los Estados tenían el derecho soberano a expulsar a los extranjeros si habían cometido un delito o una infracción administrativa, si sus actos habían vulnerado las leyes de

vías de expulsión..."(Doc. A/CN.4/642, citado, 2011).

48. De manera general, se había sugerido que siempre se mantenga la doble consideración: personas expulsadas y en vías de expulsión.

49. Art. 14 (Doc. A/CN.4/617): "1. Nadie podrá ser expulsado o devuelto a un Estado donde su derecho a la vida o su libertad personal estén en peligro de ser violados por motivos de raza, religión, nacionalidad, pertenencia a un determinado grupo social u opiniones políticas. 2. El Estado que haya abolido la pena de muerte no podrá expulsar a un extranjero condenado a muerte a un Estado en que esa persona corra el riesgo de ser ejecutada sin obtener antes garantías de que no se ejecutará la pena capital. 3. Las disposiciones de los párrafos 1 y 2 del presente artículo se aplican igualmente a la expulsión de un apátrida que se encuentre en el territorio del Estado autor de la expulsión".

50. Art. 15 (Doc. A/CN.4/617): “1. Un Estado no podrá expulsar a una persona a un país en que exista un riesgo real de que sea sometida a tortura o a tratos crueles, inhumanos o degradantes. 2. Lo dispuesto en el párrafo 1 del presente artículo se aplicará igualmente cuando el riesgo emane de personas o grupos de personas que actúen a título particular, y cuando las autoridades del Estado de destino no estén en condiciones de eludir ese riesgo mediante una protección apropiada".

51. Relator Especial, "Quinto informe...", Doc. A/CN.4/611 de 2009, citado, párrafo 7. En el proyecto aprobado en primera lectura, se lee: "Artículo 25. Protección en el Estado de tránsito de los derechos humanos del extranjero objeto de expulsión. El Estado de tránsito protegerá los derechos humanos del extranjero 
inmigración o puesto en peligro la seguridad nacional o el orden público, o si la expulsión era necesaria para la protección de la vida, la salud, los derechos o los intereses legítimos de sus nacionales".

También se observó que la expulsión debía tener una finalidad legítima y cumplir el criterio de proporcionalidad entre los intereses del Estado que expulsa y los de la persona que es expulsada (Asamblea General A/CN.4/620, 26 de enero de 2010, pár. 39). En la sesión de 2009 el Comité de redacción vuelve a presentar un informe de avance, aunque la CDI no se expide al respecto.

\section{SEXTO, SÉPTIMO Y OCTAVO INFORMES (2010-2012)}

\subsection{Sexto informe, adiciones y debates}

En el sexto informe ${ }^{53}$ y sus adiciones ${ }^{54}$ el Relator aborda varias cuestiones medulares ratio prosequi: las referidas a las expulsiones no permitidas, los motivos de la expulsión y las condiciones de detención previas a ella; ${ }^{55}$ los procedimientos de expulsión ${ }^{56}$ y la ejecución de la decisión de expulsión, recursos contra ella, relaciones entre Estados (entre el autor de la expulsión y los de tránsito y destino) y consecuencias de la expulsión: para los derechos del expulsado y en términos de responsabilidad del Estado. ${ }^{57}$

Sobre las expulsiones no permitidas, en su informe principal retoma el artículo 7 propuesto en el tercer informe y referido a la prohibición de expulsión colectiva (para "disipar ciertas reticencias expresadas por algunos miembros respecto del párrafo 3 del proyecto de artículo 7 , propuesto en el tercer informe" ${ }^{958}$; en particular, comienza discutiendo la

objeto de expulsión, de conformidad con sus obligaciones en virtud del derecho internacional".

52. Asamblea General, "Informe de la Comisión de Derecho Internacional sobre la labor realizada en su $61^{\circ}$ período de sesiones (2009) Resumen por temas, preparado por la Secretaría, de los debates de la Sexta Comisión de la Asamblea General en su sexagésimo período de sesiones", A/CN.4/620, 26 de enero de 2010, párrafo 39.

53. Relator Especial para la Expulsión de Extranjeros, "Sexto informe sobre la expulsión de los extranjeros. Presentado por Maurice Kamto, Relator Especial”, A/CN.4/625, 19 de marzo de 2010.

54. Relator Especial para la Expulsión de Extranjeros, "Sexto informe sobre la expulsión de los extranjeros. Presentado por Maurice Kamto, Relator Especial", A/CN.4/625/Add.1, 28 de mayo de 2010 y "Sexto informe sobre la expulsión de los extranjeros. Presentado por Maurice Kamto, Relator Especial". A/CN.4/625/Add.2, 9 de julio de 2010.

55. Relator Especial para la Expulsión de Extranjeros, Doc. A/CN.4/625 de 2010, párrafo 122

56. Relator Especial para la Expulsión de Extranjeros, Doc. A/CN.4/625/Add.1, de 2010, citado, párrafo 123.

57. Relator, Doc. A/CN.4/625/Add.2 de 2010, párrafo 124.

58. Comisión de Derecho Internacional, "Informe de la Comisión de Derecho Internacional $62^{\circ}$ período de sesiones (3 de mayo a 4 de junio y 5 de julio a 6 de agosto de 2010)". Asamblea General Documentos Oficiales 
previsión referida a la expulsión de poblaciones extranjeras en caso de conflicto armado. Dadas las preocupaciones manifestadas en la CDI, en el sentido de asegurar que fueran compatibles con las normas de DIH, el Relator se aboca a mostrar que lo es. Así, ya en la redacción aprobada en primera lectura quedaría como párrafo 4 con una redacción que remite a tal ordenamiento ${ }^{59}$.

Luego aborda el tema de las expulsiones encubiertas: no renovación de visados luego de un largo período de residencia, escolta policial al aeropuerto, condiciones de vida tales que suponen una expulsión implícita, etc. Deja en claro que este tipo de expulsión

(...) es, por naturaleza, contraria al derecho internacional, por un lado porque menoscaba los derechos de las personas objeto de tal expulsión $\mathrm{y}$, por tanto, las normas sustantivas en materia de expulsión que combinan el derecho a expulsar del Estado y la obligación de respetar los derechos humanos de las personas expulsadas $\mathrm{y}$, por otro lado, porque no respeta las normas de procedimiento en la materia que reconocen la posibilidad de la persona expulsada de defender sus derechos" ${ }^{\prime 60}$.

La redacción dada al proyecto de artículo, identificado con "A", la prohíbe y la define ${ }^{61}$ e incluye asimismo un análisis y proyecto de artículo consecuente sobre lo que denomina "extradición encubierta como expulsión". En las adopciones en primera y segunda lectura, la redacción final sería muy diferente, habida cuenta de las objeciones en el debate en la Comisión ${ }^{62}$.

Los motivos de expulsión, por su parte, suscitaron también mucho debate. Una pregunta previa había sido si en todos los casos los Estados debían dar motivos para la expulsión de extranjeros o, por ejemplo en el caso de la situación irregular, ella sola alcanzaba para justificarla. Partiendo de doctrina de principios del siglo XX, el Relator afirma, con tino, que el Estado no puede privar de residencia sin una justificación y que, a su vez, los motivos no pueden ser arbitrarios. (Relator Especial

$65^{\circ}$ período de sesiones, $\mathrm{A} / 65 / 10$ de 2010 , párrafo 136.

59. A saber: "El presente proyecto de artículo se entiende sin perjuicio de las normas de derecho internacional aplicables a la expulsión de extranjeros en caso de un conflicto armado en que participe el Estado expulsor".

60. Relator Especial para la Expulsión de Extranjeros, Doc. A/CN.4/625 de 2010, citado, párrafo 41.

61. Este artículo será reformulado durante la sesión, como se explica más adelante y quedará, en la versión final enviada al Comité de Redacción, como artículo 10 y 11 del proyecto aprobado en primera lectura (Doc. A/CN.4/642, citado, 2011)

62. Comisión de Derecho Internacional, "Informe de la Comisión de Derecho Internacional $62^{\circ}$ período de sesiones (3 de mayo a 4 de junio y 5 de julio a 6 de agosto de 2010)". Asamblea General Documentos Oficiales 
para la Expulsión de Extranjeros, Doc. A/CN.4/625 de 2010, párrafos 73-74) Menciona asimismo que en la actualidad, los motivos se reducen básicamente a dos: orden público y seguridad pública; (Relator Especial para la Expulsión de Extranjeros, Doc. A/CN.4/625 de 2010, párrafos 76) luego de un recorrido sobre el significado que se ha dado a ambos conceptos, deja en evidencia que "la vaguedad de los conceptos de orden público y seguridad pública expone al riesgo de que la facultad de apreciar la conducta del extranjero se ejerza en forma arbitraria por el Estado autor de la expulsión" (Relator Especial para la Expulsión de Extranjeros, Doc. A/CN.4/625 de 2010, pár. 99) y que algunos criterios de apreciación son necesarios. Uno de ellos es que haya un justo equilibrio entre la protección del orden público y el interés de la persona, en particular teniendo en cuenta la jurisprudencia que señala que para

(...) valorar si la medida restrictiva es proporcionada, conviene tener en cuenta la naturaleza de la gravedad de la infracción cometida, la duración de la residencia en el territorio del Estado miembro de acogida, el período transcurrido desde la comisión de la infracción, la situación familiar del interesado y la gravedad de las dificultades que pueden presentarse al cónyuge y los hijos en el país de origen del interesado. (Relator Especial para la Expulsión de Extranjeros, Doc. A/CN.4/625 de 2010, pár. 109)

Por último, analiza otros motivos de expulsión invocados en las prácticas estatales: interés superior del Estado, violación de la ley, condena a pena de prisión, incumplimiento de formalidades administrativas (destacando que en contextos de libre circulación, el incumplimiento de formalidades administrativas no puede constituir una perturbación al orden o la seguridad públicos suficientes para justificar la deportación), (Asamblea General Documentos Oficiales $65^{\circ}$ período de sesiones, A/65/10 de 2010, pár. 143) salud pública, buenas costumbres, las actividades políticas, los motivos culturales, la entrada ilegal, el incumplimiento de las condiciones de admisión, motivos económicos, para impedir determinadas conductas o como represalia, todos con abundantes citas de normas y jurisprudencia comparada), formulando el proyecto de artículo 9 en tales términos. ${ }^{63}$

$65^{\circ}$ período de sesiones, $\mathrm{A} / 65 / 10$ de 2010 , párrafos $153-154$

63. Proyecto de artículo 9: "Motivos de expulsión. 1. Toda decisión de expulsión deberá estar motivada. 2. Un Estado podrá, en particular, expulsar a un extranjero por motivos de orden público o de seguridad pública, de conformidad con la ley. 3. Un Estado no podrá expulsar a un extranjero por un motivo contrario al derecho internacional. 4. El motivo de expulsión deberá ser evaluado de buena fe y de manera razonable, teniendo en cuenta la gravedad de los hechos y la inminencia de la amenaza que suponen, a la luz de las circunstancias y del comportamiento de la persona de que se trate". Estos motivos de expulsión serán, en la aprobación en 
El último tema que aborda este 6to. informe es el de las condiciones de detención; luego de reconocer que ni siquiera hay acuerdo sobre la palabra a emplear (detención, retención, etc.), propone superar este "pudor semántico" vía el uso de la palabra que realmente refleja que se trata de una privación de libertad: "detención". Usa como ejemplos las prácticas de ocho países (Alemania, España, Estados Unidos, Francia, Gran Bretaña, Grecia, Sudáfrica, Guinea Ecuatorial) y con cita de numerosa jurisprudencia en derechos humanos y otros documentos, como ser el "Conjunto de Principios para la protección de todas las personas sometidas a cualquier forma de detención o prisión" y los informes de la Relatoría para los derechos humanos de los migrantes, aborda las condiciones de detención, su duración y las condiciones de ejecución de la expulsión. ${ }^{64}$

Sobre los procedimientos de expulsión, que será la Adición 1 al Informe, (Doc. A/CN.4/625/Add.1 de 28 de mayo de 2010) el Relator destaca en primer lugar la distinción entre los extranjeros que se encontraban en el territorio de un Estado en situación legal y los que estaban en situación ilegal; muy interesantemente, deja claro que en su opinión, "si bien se trataba de una distinción de innegable pertinencia en lo referente a las normas de procedimiento, no debía tenerse en consideración en relación con los derechos humanos de la persona expulsada". (Doc. A/65/10 de 2010, citado, párrafo 142) Asimismo, aunque la gran variedad de prácticas le había llevado a la conclusión que era mejor dejarlo librado a las legislaciones internas, las garantías ofrecidas a las personas en situación irregular debían ser similares. No obstante, una consideración especial merecerían las personas que han residido por largo tiempo en el territorio del Estado que expulsa, ${ }^{65}$ cuestión que había sido objeto de

primera lectura, los artículos 4 y 5

64. Proyecto de artículo B: "Obligación de respetar los derechos humanos del extranjero durante su expulsión o en el período de detención con miras a su expulsión 1. La expulsión de un extranjero deberá realizarse de conformidad con las normas internacionales de derechos humanos. Deberá llevarse a cabo con humanidad, sin rigores innecesarios y respetando la dignidad de la persona de que se trate. 2. a) La detención de un extranjero con miras a su expulsión deberá realizarse en un lugar adecuado, distinto del lugar en que estén detenidas las personas condenadas a penas privativas de libertad, y respetando los derechos humanos de la persona de que se trate. b) La detención de un extranjero expulsado o en vías de expulsión no deberá tener carácter punitivo. 3. a) El período de detención no podrá ser indefinido. Deberá limitarse al tiempo razonablemente necesario para ejecutar la decisión de expulsión. Quedan prohibidas las detenciones de duración excesiva. b) La prolongación del período de detención solo podrá ser decidida por un órgano judicial o por una persona que pueda ejercer funciones judiciales. 4. a) La decisión de detención deberá examinarse periódicamente, en plazos determinados, sobre la base de criterios precisos definidos por la ley. b) Se pondrá fin a la detención cuando la decisión de expulsión no pueda ejecutarse por motivos que no sean imputables a la persona de que se trate". Salvo el apartado 1, el resto pasará con pocas modificaciones a la aprobación en primera lectura.

65. "Proyecto de artículo A1. "Ámbito de aplicación de las [presentes] normas de procedimiento 1. Los proyectos de artículos de la presente parte se aplican en caso de expulsión de un extranjero que se halle legalmente [en situación regular] en el territorio del Estado que lo expulsa. 2. Sin embargo, un Estado puede aplicarlas también a la expulsión de un extranjero que haya entrado ilegalmente en su territorio, en particular cuando dicho extranjero goza en él de un estatuto particular previsto en la ley, o cuando ha residido allí 
debate y que termina siendo sustancialmente modificada. (Doc. A/65/10 de 2010, citado, pár. 162-167)

En segundo lugar, aborda las normas de procedimiento. Luego de algunas consideraciones generales sobre el carácter de la expulsión (castigo, medida administrativa), formula una propuesta en torno a las garantías del procedimiento: la primera y más generalmente aceptada es que sea conforme a la ley (proyecto de artículo "B.1") mientras que el derecho a exponer las razones de su caso, ser informado, a impugnar la decisión, a ser oído, a estar presente, a que el recurso sea eficaz, a la protección consular, a un asesor, a un traductor e intérprete, quedarán formuladas en un solo artículo (“C.1").

En la Adición 2 (que sería tratada por la CDI en las sesiones del año siguiente), se aborda la ejecución de la decisión de expulsión, los recursos contra ella, las relaciones entre Estados (entre el autor de la expulsión y los de tránsito y destino) y las consecuencias de la expulsión -para los derechos del expulsado y en términos de responsabilidad del Estado. Sobre la ejecución, se aborda la tensión entre efectividad y derechos de la persona expulsada: los ejecutores de las medidas "de acompañamiento" han ocasionado, en más de una ocasión, la muerte de la persona trasladada; (Doc. A/CN.4/625/Add.2 de 9 de julio de 2010, pár. 10) eso será el artículo D.1. En cuanto a los recursos, deja en claro que se aplican las normas generales en derechos humanos que garantizan el derecho al recurso -art. 8 de la DUDH, art. 13 del Convenio Europeo de Derechos Humanos, art. 13 PIDCyP, Recomendación General nro. 30 del Comité contra la Discriminación Racial- y que en la actualidad, este derecho tiene valor consuetudinario. (Doc. A/CN.4/625/Add.2 de 9 de julio de 2010, pár. 49) Algunas características de este recurso son: el efecto suspensivo, necesario para ser un recurso efectivo (Doc. A/CN.4/625/Add.2 de 9 de julio de 2010, pár. 31,51 y 54) y el plazo breve para resolverlo, aspectos para los cuales no se termina previendo ninguna norma específica. (Doc. A/CN.4/625/Add.2 de 9 de julio de 2010, pár. 59) Finalmente la CDI aprobaría una disposición al respecto. ${ }^{66}$

Sobre las relaciones entre Estados, distingue aquellas del Estado expulsor con: (i) con el Estado de destino, lo que será el proyecto de artículo E.1 (que pasará al comité de redacción como artículo 17); (ii) con el Estado de tránsito, donde debe contar de igual protección que en el Estado que expulsa (F.1, que pasará como artículo 20). 
Por último, en la sección de consecuencias, propone un artículo para evitar la vieja práctica de expulsión a los fines de confiscar los bienes de la persona extranjera (proyecto de artículo G.1, que pasará como artículo 25), al tiempo que busca resguardar el reingreso si la expulsión ha sido ilegal (H.1) ${ }^{67}$ y asegurar la consecuente responsabilidad del Estado, al afirmar que "el principio de que el Estado que expulsa a un extranjero en violación de las normas de derecho internacional incurre en responsabilidad internacional está bien asentado desde hace largo tiempo", según el proyecto de artículo I.1 que pasará como art. 26. (Doc. A/CN.4/625/Add.2 de 9 de julio de 2010, párrafo $166 .{ }^{68}$ Por último, también aborda la protección diplomática (J.1, luego 27). Todas estas propuestas de la Adición 2 serán finalmente tratadas en la sesión del año siguiente (2011).

En su debate, la CDI incluye, además del examen de este informe, las reestructuraciones y nuevo plan de trabajo propuestas por el Relator en 2009; a grandes rasgos, se respaldó la nueva redacción dada por el Relator con la salvedad de algunas puntualizaciones ${ }^{69}$. En una de sus primeras sesiones, decide enviar al Comité de Redacción las propuestas de artículos 8 a 15 según su forma reordenada, esto es, todos los proyectos de artículos que contenía menos el 16 referido a la extradición encubierta. Poco después y en diferentes sesiones entre 2010 y 2011, decide enviar al Comité de Redacción todos los demás artículos propuestos (A a J), algunos con modificaciones.

\subsection{Séptimo y octavo informes $(2011,2012)$}

El séptimo informe es diferente de todos los anteriores y hasta el final (el noveno), todos abordarán cuestiones particulares y temas de coyuntura. Mientras que los previos buscaban avanzar en la codificación y desarrollo progresivo de normas aplicables, este séptimo informe ${ }^{70}$ trae las novedades producidas en el campo en los últimos años: (i) la iniciativa popular suiza sobre expulsión de extranjeros; (ii) el proyecto francés, ambos dirigidos a la cancelación de la residencia o desnacionalización y posterior expulsión frente a ciertos delitos; (iii) la sentencia de la CIJ en el caso Ahmadou Sadio Diallo, la primera de esta

\footnotetext{
66. En la aprobación en primera lectura revistaría el efecto suspensivo del recurso (artículo 27).

67. Este artículo pasará finalmente al Comité de Redacción como artículo 24; en la aprobación en primera lectura será el derecho de readmisión (art. 29).

68. Doc.A/CN.4/625/Add. 2 de 9 de julio de 2010, párrafo 166.

69. Por ejemplo, que no apareciera como un texto que los Estados pudieran aceptar o no sino más bien, como principios de Derecho Internacional (Doc. A/65/10 de 2010, párrafo 128), que en la referencia a dignidad se atuviera a la definición del PIDCyP (párrafo 129), que se incluyera la "discriminación positiva" en la propuesta sobre no discriminación (párrafo 130) y que se reforzara la protección de la persona cuando el país al que era expulsada podría implicarle el riesgo de aplicación de la pena de muerte (párrafo 133).

70. Relator Especial para la Expulsión de Extranjeros, "Séptimo informe sobre la expulsión de los 
Corte sobre expulsión de extranjeros. ${ }^{71}$ Asimismo, este informe incluye también una muy útil reordenación de los artículos debatidos, con indicación del/os documento/s donde se puede encontrar la versión final a la fecha.

En sus debates, la CDI trata la Adición 2 del informe de 2010 junto con este séptimo informe; por demás, este sería el último informe antes de que se presentara el conjunto de proyectos de artículo elaborados sobre el tema en cuestión para su eventual aprobación por la CDI. Asimismo, la Comisión incorpora en sus discusiones dos órdenes de documentos: (i) los avances del Comité de Redacción, sobre los cuales toma nota ${ }^{72}$, a la vez que le reenvía la nueva reordenación. Además de los artículos D1 a J1, envía también al Comité de redacción el proyecto de artículo 8 sobre extradición en su nueva versión; ${ }^{73}$ (ii) los comentarios enviados por los Estados en $2008^{74}$ por Alemania, Mauricio, Rusia y Suiza y $2010^{75}$, donde se sumarían varios Estados más. En sus debates, se plantearon nuevamente objeciones a la tarea de la CDI en general y a varios artículos en particular: entre los más debatidos, la extradición en relación con la expulsión (art. 8) y el recurso contra la decisión de expulsión, en particular, si se incluía el efecto suspensivo.

Por su parte, en los debates en la Sexta Comisión, además de insistir con la pregunta sobre la utilidad del trabajo de la CDI (y de mostrar en general, posturas divididas en los diferentes proyectos de artículos) se solicitó, indirectamente, que se prestara mayor atención a las facultades del Estado y menos a los derechos de los extranjeros al sostener que "el proyecto de artículos no sólo debía asegurar un elevado nivel de protección para los extranjeros sino que resultar aceptable con carácter general para los Estados". ${ }^{76}$

extranjeros. Presentado por Maurice Kamto, Relator Especial”, A/CN.4/642, 4 de mayo de 2011.

71. Además del deber de informar el motivo de la expulsión y notificar a las autoridades consulares, la Corte Internacional de Justicia se aboca centralmente al derecho a la propiedad del extranjero que resulta expulsado (Relator, Doc. A/CN.4/642 de 2011, párrafos 33 y ss.). Finalmente, declara que la República Democrática del Congo es internacionalmente responsable.

72. Comisión de Derecho Internacional, "Informe de la Comisión de Derecho Internacional $63^{\circ}$ período de sesiones (26 de abril a 3 de junio y 4 de julio a 12 de agosto de 2011)". Asamblea General Documentos Oficiales Sexagésimo sexto período de sesiones, A/66/10 de 2011, párrafo 214.

73. El proyecto de artículo 8 revisado, reproducido en la nota 1268 del informe de la Comisión sobre los trabajos del $62^{\circ}$ período de sesiones (Doc. A/65/10), decía así: "Expulsión en relación con la extradición. Una persona solo podrá ser expulsada a un Estado que solicite su extradición, o a un Estado que tenga un interés particular en que esa persona sea extraditada al Estado que solicite la extradición, cuando se cumplan las condiciones para la expulsión que se estipulan en derecho internacional [o en las disposiciones del presente proyecto de artículos]". En la aprobación en primera lectura su formulación sería mucho más simple: "Un Estado no recurrirá a la expulsión con el fin de eludir un procedimiento de extradición en curso".

74. Expulsión de los extranjeros. Información y observaciones recibidas de los gobiernos, Doc. A/CN.4/604, 26 de agosto de 2008 .

75. Expulsión de los extranjeros. Información y observaciones recibidas de los gobiernos. Doc. A/CN.4/628, 26 de abril de 2010.

76. Asamblea General, "Informe de la Comisión de Derecho Internacional sobre la labor realizada en su $63^{\circ}$ período de sesiones. Resumen por temas, preparado por la Secretaría, de los debates de la Sexta Comisión de la 
En el octavo informe, el Relator concentra estas objeciones e intenta, una vez más, dar respuesta a ellas. Sobre la crítica a la tarea emprendida por la CDI, su respuesta es contundente: "ningún otro tema incluido en el programa de la Comisión en los últimos quinquenios presenta una base tan rica para su codificación...varios temas tratados por la CDI...no estaban respaldados por tanto material jurídico". (Relator Especial para la Expulsión de Extranjeros, A/CN.4/651, 22 2012, pár. 56) Algunas de ellas, como la preocupación de la delegación de los Estados Unidos sobre la referencia al principio de no devolución, merecen acertadas respuestas tales como que "en el estado actual del derecho internacional de los derechos humanos, el Relator Especial no encuentra nuevos datos que añadir a [las] aclaraciones" efectuadas en los informes anteriores." (Relator Especial para la Expulsión de Extranjeros, A/CN.4/651, 22 2012, pár. 7) Asimismo, hace notar que algunas críticas ya fueron recogidas y por tanto, modificada la redacción de los proyectos de artículos; frente a otras propuestas, propone nuevas redacciones.

Los debates de la CDI al respecto son brevísimos (resume los argumentos del Relator en dos párrafos y luego reproduce el proyecto de artículos según se adoptó en primera lectura, junto con los comentarios a continuación), por lo cual se omiten. En cambio, en la Sexta Comisión se criticó la atención prestada a las prácticas regionales, a la jurisprudencia de órganos creados en virtud de tratados y al único régimen que unificaba, en términos de derechos, a extranjeros con residencia ilegal. ${ }^{7}$ En cuanto a los comentarios particulares, muestra el desfasaje (que el Relator ya había señalado en alguna oportunidad) con los avances dentro de la CDI: por ejemplo, sugieren que se incluya un artículo sobre la detención cuando un artículo tal ya se había incluido en el Sexto Informe del relator, dos años antes. (Asamblea General, A/CN.4/657, 2013, pár. 10)

\section{ADOPCIÓN EN PRIMERA LECTURA, NOVENO INFORME Y SEGUNDA LECTURA (2012 A 2014)}

En la misma sesión de consideración del octavo informe (2012), la CDI decide aprobar el proyecto de artículos en primera lectura; ${ }^{79}$ poco después en la misma sesión, aprobaría los comentarios y se decide enviar a los gobiernos el proyecto de artículos para que efectuaran

Asamblea General en su sexagésimo sexto período de sesiones",A/CN.4/650, 20 de enero de 2012, párrafo 16. 77. Idem, párrafo 7 .

78. Asamblea General, "Informe de la Comisión de Derecho Internacional sobre la labor realizada en su $63^{\circ}$ y $64^{\circ}$ período de sesiones. Resumen por temas, preparado por la Secretaría, de los debates de la Sexta Comisión de la Asamblea General en su sexagésimo sexto período de sesiones", A/CN.4/657, 18 de enero de 2013, párrafos 3-4

79. Se omite aquí una referencia detallada pues en la gran mayoría de las notas al pie de cada proyecto de 
comentarios, con deadline al 1 de enero de 2014. Esto implicaba el triunfo de la postura del Relator y de muchas otras delegaciones: primero, que se lograran superar las objeciones a la tarea misma de la Comisión; segundo, que la forma final fuera un proyecto de artículos.

En su último informe, el noveno, ${ }^{80}$ el Relator se aboca a compendiar y contestar los comentarios enviados por los Estados; salvo los proyectos de artículos 25 y 28, todos recibieron observaciones. Aunque desde la Relatoría se habían solicitado comentarios desde el inicio de los trabajos, no fue sino frente al proyecto terminado que los Estados realmente se preocuparían por enviar comentarios. Esta ausencia del proceso se notará en las observaciones enviadas, referidas por ejemplo al método de la CDI y la viabilidad del tema, frente a las cuales el Relator se limita a reiterar que si se siguieran los criterios propuestos por los Estados, ello implica cuestionar todo el trabajo de la CDI desde sus inicios, ya que se ha seguido el mismo enfoque y tratamiento. (Relator Especial para la Expulsión de Extranjeros, A/CN.4/670, 2014, pár. 6) En cuanto a los comentarios particulares, además de ser extensos son, con frecuencia, poco importantes y no hacen a la forma definitiva adoptada por el proyecto.

Entre la primera y segunda lectura, los cambios operados a consecuencia de estos comentarios apuntaron a (i) tratar de relativizar algunas cuestiones; (ii) referir a regímenes específicos (incluso de derecho interno), y en minoría, a (iii) lograr excepciones. Así, por ejemplo, se suprimió la referencia a extranjeros presentes legal o ilegalmente en el territorio (art. 1), se excluyó a personas solicitantes de la condición de refugio (art. 6), se eliminó la prohibición de discriminación en todos los derechos (art. 15), se agrega que la detención puede ser prolongada por otra autoridad distinta a la judicial, aunque con control de esta (art. 19) y en cuanto al efecto suspensivo del recurso, se agregó que sería tal "cuando haya riesgo real de perjuicio grave o irreversible". Por lo demás, no hubo prácticamente más modificaciones.

Así, el 5 de agosto de 2014 y luego de agradecer la realmente inmensa y paciente labor del Relator, la Comisión decide recomendar a la Asamblea General que:

a) Tomase nota del proyecto de artículos sobre la expulsión de extranjeros en una resolución, incluyera los artículos en un anexo de dicha resolución y alentase a que se le diera la máxima difusión; 
b) Considerase la posibilidad de, en una etapa posterior, elaborar una convención sobre la base del proyecto de artículos. ${ }^{81}$

Dado que por lo general con la segunda lectura se da por terminado el examen de la cuestión, sólo resta esperar la recepción por la Asamblea General, señalándose el $72^{\circ}$ período de sesiones (2017) como la siguiente oportunidad para que se trate el tema. (Documento A/c.6/69/1.15, punto 4)

\section{DISCUSIÓNY CONCLUSIONES}

En este artículo se intentó dar una visión panorámica del trabajo que, durante una década, se desarrolló en el seno de la Comisión de Derecho Internacional de las Naciones Unidas a propósito de la expulsión de personas extranjeras y a través del Relator para la cuestión. No siendo posible (dada la extensión de esta contribución pero también, su intención) dar cuenta detalladamente de los debates o de previsiones específicas, el principal aporte de esta revisión radica, entiendo, en sistematizar un trabajo que ha sido abordado de manera dispersa (como un tópico más dentro del trabajo de la Comisión) y que no ha merecido atención específica por parte de los estudiosos de la migración al punto que de hecho, la existencia misma del proyecto de artículos ha pasado desapercibida.

La segunda intención fue poner en evidencia cómo la perspectiva de derechos humanos ha permeado (receptando los más recientes desarrollos) dentro de un abordaje donde, en un núcleo claramente de derecho internacional público como es la Comisión de Derecho Internacional, prima la visión de la soberanía estatal. Justamente, la intersección entre el derecho internacional clásico y la primacía de la soberanía estatal (lo que da por resultado un "derecho a expulsar" como punto de partida) y las normas de derechos humanos fue identificada, con atino, como una cuestión pendiente de la que podría ocuparse la CDI: equilibrar el mal llamado "derecho" de los Estados con los de las personas extranjeras.

En rigor, el término "facultad" resulta más apropiado, ya que se trata de prerrogativas que se ejercen frente a personas. La idea de "derecho" (del Estado) frente a "derechos" de las personas nos dan una falsa idea de paridad que debería equilibrar ambos grupos de derechos (con sus independientes centros de intereses) cuando en realidad, el Estado no tiene derechos propios frente a las personas sino que, desde una visión de derechos, se trata de una entidad creada por esta para ciertos fines, entre ellos, la protección de sus derechos, los humanos. (Cançado, 2006)

Presentado por el Sr. Maurice Kamto, Relator Especial", A/CN.4/670, 25 de marzo de 2014.

81. Comisión de Derecho Internacional, "Informe de la Comisión de Derecho Internacional $66^{\circ}$ período de sesiones ( 5 de mayo a 6 de junio y 7 de julio a 8 de agosto de 2014)". Asamblea General Documentos Oficiales 
Frente a esto, los debates al interior de la Comisión hicieron de esta una caja de resonancia de los recelos de los Estados a ceder aristas de control sobre el último bastión de población. Así, por ejemplo, cuando se objetaba sobre la base de las "dificultades para codificar", del tema en sí mismo o la falta de una práctica uniforme (frente a lo cual el Relator no se cansó de insistir que la metodología fue similar a la seguida en otros temas que abordó la CDI) ello nos pone en la pista que tras estas objeciones formales, se enfila claramente la resistencia de los Estados a que los organismos internacionales que pueden generar alguna vinculancia siquiera se ocupen de la cuestión. Esto es, a que el derecho internacional se ocupe, siquiera desde su fuente "doctrina", de un tema que entienden inscrito en su orden doméstico. El problema, por supuesto, no es la diversidad de las prácticas, sino que justamente no se atente contra el hecho de que sigan siendo diversas según el margen de apreciación estatal, o sea, el gusto, la política y la oportunidad de cada cual. En palabras de Murphy (2014) "such positions perhaps highlight a central difficulty with the project, namely that it attempts to codify a series of rules in an area where states already have long-standing, detailed, divergent, and ever-changing national laws and regulations that touch upon sensitive national security concerns"(p. 5) por no mencionar políticos y electoralistas en particular.

Comparto en este sentido el estupor del Relator, al decir que "le parecía sorprendente que, aun habiendo llegado a este punto, algunos miembros siguieran haciéndose preguntas sobre la naturaleza de la labor que debía llevar a cabo la Comisión" (Doc. A/66/10 de 2011, pár. 258) y una de las explicaciones que ensaya al respecto es que "los trabajos de la Comisión de Derecho Internacional sobre la expulsión de extranjeros iban siempre por delante de los informes presentados a la Asamblea General sobre el tema”. (Doc. A/CN.4/651, 22 de marzo de 2012, pár. 54) Sin embargo, sobre lo que el Relator llama "desfasaje" entre las discusiones en la CDI y en la Sexta Comisión, sobre el final la impresión que queda es que sencillamente, las delegaciones no leen los documentos para el debate. Aunque inicialmente el Relator sugiere que la no sincronicidad (la insistencia en cuestiones a las que ya se había referido o bien, el reclamo por cuestiones no incorporadas que ya estaban en el plan de trabajo como tema a incorporar) se debe a los tiempos de la Sexta Comisión y al procesamiento de los documentos, en su último informe lamenta, directamente, que incluso los comentarios al proyecto en primera lectura denoten que al parecer, los Estados no han leído el proyecto y sus comentarios. (Doc. A/CN.4/651, 2012, pár. 73) Luego de leer los debates en uno y otro espacio, huelga decir que lo mismo debe lamentarse en los anteriores nueve años de trabajo. 
En cuanto a la forma final que debía adoptar, puede por supuesto advertirse que los pocos Estados emisores de población se inclinaban por la forma más fuerte de futura vinculancia (proyecto de artículos) mientras que los receptores insistían con principios, directrices, "buenas prácticas" (Grecia) u "orientaciones" (Reino Unido). Volviendo aquí a las tres cuestiones que debe definir la CDI al completar un trabajo (forma de empaquetado, caracterización y recomendación), podría decirse que la perspectiva de derechos de las personas extranjeras ha ganado bastante: aunque no consiguió que la CDI recomendara directamente un tratado, logró posicionarse como un proyecto de artículos. Para salvar las disidencias sobre si se trataba de "desarrollo progresivo" o "codificación", en los comentarios a cada artículo se dejó constancia sobre una u otra caracterización.

Por último, querría volver sobre una última cuestión que refería en el cuerpo de este artículo: cómo opera el principio de discriminación, el cual parecería no pertinente a los efectos de la expulsión pues, por definición, los nacionales no pueden ser expulsados. Dentro de espacios de libre circulación es posible afirmar su equiparación y por tanto, ningún nacional podrá ser expulsado y tampoco, ningún extranjero de la Comunidad Europea, del MERCOSUR, de la Comunidad Andina, etc. La pregunta subsiste entre espacios asimétricos y nos lleva a inquirirnos sobre la misma existencia de los derechos humanos de las personas extranjeras frente al Estado del cual no son nacionales; en lugar de dar la discusión derecho por derecho, la verdadera disputa es a nivel de la subjetividad, del posicionamiento mismo de la persona extranjera como sujeto de derecho. Una discusión que deviene no menor en este 2017, donde el órgano plenario de las Naciones Unidas tendrá entre manos dar tratamiento y forma al borrador de proyecto elaborado por el Relator, en el marco de un contexto regional (con D. Trump a la cabeza) de fronteras reforzadas.

Para terminar, lamento personalmente la desdibujada participación argentina en algunos espacios: si bien formó parte, en varios períodos, del comité de redacción del proyecto de artículos, ni en los debates en la Sexta Comisión ni en los comentarios por escrito tuvo activa participación. En ambos grupos, la participación fue mayoritariamente de países receptores de poblaciones extranjeras; de los pocos países emisores de población que participaron, estuvieron El Salvador y Perú. Argentina cuenta con una legislación modelo que reconoce el derecho humano a migrar (que de hecho es mencionada en el Memorándum inicial de la Secretaría) y hubiera sido importante apoyar la, con frecuencia, solitaria posición del Relator en pos de avanzar en los derechos humanos de las personas extranjeras. 


\section{REFERENCIAS BIBLIOGRÁFICAS}

Asamblea General de Naciones Unidas, Declaración sobre los derechos humanos de los individuos que no son nacionales del país en que viven, Resolución 40/144, de 13 de diciembre de 1985.

Asamblea General, (2005) Informe de la Comisión de Derecho Internacional sobre la labor realizada en su $56^{\circ}$ período de sesiones 2004. Resumen por temas, preparado por la Secretaría, de los debates de la Sexta Comisión de la Asamblea General en su sexagésimo período de sesiones, A/CN.4/549, 31 de enero de 2005 ,

Asamblea General, (2006) Informe de la Comisión de Derecho Internacional sobre la labor realizada en su $57^{\circ}$ período de sesiones 2005. Resumen por temas, preparado por la Secretaría, de los debates de la Sexta Comisión de la Asamblea General en su sexagésimo período de sesiones, A/CN.4/560, 13 de enero de 2006.

Asamblea General, (2007) Informe de la Comisión de Derecho Internacional sobre la labor realizada en su $58^{\circ}$ período de sesiones 2006. Resumen por temas, preparado por la Secretaría, de los debates de la Sexta Comisión de la Asamblea General en su sexagésimo período de sesiones, A/CN.4/577, 19 de enero de 2007

Asamblea General, (2008) Informe de la Comisión de Derecho Internacional sobre la labor realizada en su $59^{\circ}$ período de sesiones 2007. Resumen por temas, preparado por la Secretaría, de los debates de la Sexta Comisión de la Asamblea General en su sexagésimo período de sesiones", A/CN.4/588, 24 de enero de 2008.

Asamblea General, (2010). Informe de la Comisión de Derecho Internacional sobre la labor realizada en su $61^{\circ}$ período de sesiones 2009. Resumen por temas, preparado por la Secretaría, de los debates de la Sexta Comisión de la Asamblea General en su sexagésimo período de sesiones", A/CN.4/620, 26 de enero de 2010

Asamblea General, (2012) Informe de la Comisión de Derecho Internacional sobre la labor realizada en su $63^{\circ}$ período de 
sesiones 2011. Resumen por temas, preparado por la Secretaría, de los debates de la Sexta Comisión de la Asamblea General en su sexagésimo sexto período de sesiones", A/CN.4/650, 20 de enero de 2012

Asamblea General, (2013). Informe de la Comisión de Derecho Internacional sobre la labor realizada en su $63^{\circ}$ y $64^{\circ}$ período de sesiones. Resumen por temas, preparado por la Secretaría, de los debates de la Sexta Comisión de la Asamblea General en su sexagésimo sexto período de sesiones", A/CN.4/657, 18 de enero de 2013

Asamblea General, Doc. A/64/10.

Cançado Trindade, A., (2006).El derecho internacional de los Derechos Humanos en el siglo XXI, Editorial Jurídica de Chile, Santiago de Chile

Comisión de Derecho Internacional, (2000) Informe sobre la labor realizada en su $52^{\circ}$ período de sesiones $\left(1^{\circ}\right.$ de mayo a 9 de junio y 10 de julio a 18 de agosto de 2000), Asamblea General, Documentos oficiales $55^{\circ}$ período de sesiones, A/55/10 de 2000 . Anexo.

Comisión de Derecho Internacional, (2004) Informe de la Comisión de Derecho Internacional $56^{\circ}$ período de sesiones ( 3 de mayo a 4 de junio y 5 de julio a 6 de agosto de 2004), Asamblea General Documentos Oficiales $59^{\circ}$ período de sesiones, A/59/10 de 2004 .

Comisión de Derecho Internacional, (2006) Expulsión de extranjeros. Memorándum preparado por la Secretaría, UN/Doc. A/CN.4/565, 10 de julio de 2006.

Comisión de Derecho Internacional, (2005) Informe de la Comisión de Derecho Internacional $57^{\circ}$ período de sesiones ( 2 de mayo a 3 de junio y 11 de julio a 5 de agosto de 2005), Asamblea General Documentos Oficiales $60^{\circ}$ período de sesiones, A/60/10 de 2005

Comisión de Derecho Internacional, (2007) Informe de la Comisión de Derecho Internacional $59^{\circ}$ período de sesiones ( 7 de mayo a 5 de junio y 9 de julio a 10 de agosto de 2007). Asamblea General Documentos Oficiales $62^{\circ}$ período de sesiones, A/62/10 de 2007 
Comisión de Derecho Internacional, (2008) Informe de la Comisión de Derecho Internacional $60^{\circ}$ período de sesiones ( 5 de mayo a 6 de junio y 7 de julio a 8 de agosto de 2008). Asamblea General Documentos Oficiales $63^{\circ}$ período de sesiones, A/63/10 de 2008 .

Comisión de Derecho Internacional, (2009) Informe de la Comisión de Derecho Internacional $61^{\circ}$ período de sesiones (4 de mayo a 5 de junio y 6 de julio a 7 de agosto de 2009). Asamblea General Documentos Oficiales $63^{\circ}$ período de sesiones, A/64/10.

Comisión de Derecho Internacional, (2010) Informe de la Comisión de Derecho Internacional $62^{\circ}$ período de sesiones ( 3 de mayo a 4 de junio y 5 de julio a 6 de agosto de 2010). Asamblea General Documentos Oficiales $65^{\circ}$ período de sesiones, A/65/10 de 2010 .

Comisión de Derecho Internacional, (2011) Informe de la Comisión de Derecho Internacional $63^{\circ}$ período de sesiones ( 26 de abril a 3 de junio y 4 de julio a 12 de agosto de 2011). Asamblea General Documentos Oficiales Sexagésimo sexto período de sesiones, A/66/10 de 2011

Comisión de Derecho Internacional, (2014) Informe de la Comisión de Derecho Internacional $66^{\circ}$ período de sesiones ( 5 de mayo a 6 de junio y 7 de julio a 8 de agosto de 2014). Asamblea

Comité de Derechos Humanos, (1999) Observación General nro. 27, Comentarios generales adoptados por el Comité de los Derechos Humanos, Artículo 12 -La libertad de circulación, Doc. HRI/GEN/1/Rev.

Convención Internacional sobre la protección de todos los derechos de los trabajadores migratorios y de sus familiares, Adoptada por la Asamblea General en su resolución 45/158, de 18 de diciembre de 1990.

Expulsión de los extranjeros. Información y observaciones recibidas de los gobiernos. Doc. A/CN.4/628, 26 de abril de 2010.

Expulsión de los extranjeros. Información y observaciones recibidas de los gobiernos, Doc. A/CN.4/604, 26 de agosto de 2008.

General Documentos Oficiales Sexagésimo noveno período de sesiones, A/69/10, párrafo 42. 
Guía analítica para el tópico Expulsión de extranjeros. Disponible en: http://legal.un.org/ilc/guide/9_12.htm

Informe de la Relatora Especial sobre los derechos humanos de los migrante, Doc. E/CN.4/2005/85.

Martínez Pérez, O., (2013) La expulsión de extranjeros y la labor de organismos internacionales al respecto. Comentarios de cátedra", Revista de la Facultad de Ciencias Sociales y Jurídicas de Elche, Vol. 1, No. 9

Matheson, M., (2014) The Fifty-Fifth Session of the International Law Commission", American Journal of International Law, Vol. 98, No. 2

Murphy, S., (2014) "The Expulsion of Aliens (Revisited) and Other Topics: The Sixty-Sixth Session of the International Law Commission", GW Law School Public Law and Legal Theory, Paper no. 2014-59

Pinto, M.,(2004) El derecho internacional. Vigencia y desafíos en un escenario globalizado, Fondo de Cultura Económica, Buenos Aires.

Relator Especial para la Expulsión de Extranjeros, Cuarto informe sobre la expulsión de extranjeros Presentado por el Sr. Maurice Kamto, Relator Especial, A/CN.4/594, 24 de marzo de 2008

Relator Especial para la Expulsión de Extranjeros, Expulsión de Extranjeros. Proyectos de artículo sobre la protección de los derechos humanos de la persona expulsada o en vías de expulsión, reordenados por el Relator Especial, Sr. Maurice Kamto, a la luz del debate celebrado en sesión plenaria durante la primera parte del presente período de sesiones, A/CN.4/617, 21 de julio de 2009

Relator Especial para la Expulsión de Extranjeros, Informe preliminar sobre la expulsión de los extranjeros presentado por el Sr. Maurice Kamto, Relator Especial, UN Doc. A/CN.4/554, 4 de abril de 2005

Relator Especial para la Expulsión de Extranjeros, Noveno informe sobre la expulsión de extranjeros. Presentado por el Sr. Maurice Kamto, Relator Especial,A/CN.4/670, 25 de marzo de 2014. 
Relator Especial para la Expulsión de Extranjeros, Octavo informe sobre la expulsión de extranjeros. Presentado por Maurice Kamto, Relator Especial, A/CN.4/651,22 de marzo de 2012.

Relator Especial para la Expulsión de Extranjeros, Quinto informe sobre la expulsión de extranjeros Presentado por el Sr. Maurice Kamto, Relator Especial, A/CN.4/611, 27 de marzo de 2009

Relator Especial para la Expulsión de Extranjeros, Segundo informe sobre la expulsión de los extranjeros presentado por el Sr. Maurice Kamto, Relator Especial, UN Doc. A/CN.4/573, 20 de julio de 2006

Relator Especial para la Expulsión de Extranjeros, Séptimo informe sobre la expulsión de los extranjeros. Presentado por Maurice Kamto, Relator Especial", A/CN.4/642, 4 de mayo de 2011.

Relator Especial para la Expulsión de Extranjeros, Sexto informe sobre la expulsión de los extranjeros. Presentado por Maurice Kamto, Relator Especial", A/CN.4/625, 19 de marzo de 2010.

Relator Especial para la Expulsión de Extranjeros, Sexto informe sobre la expulsión de los extranjeros. Presentado por Maurice Kamto, Relator Especial”.A/CN.4/625/Add.2, 9 de julio de 2010.

Relator Especial para la Expulsión de Extranjeros, Tercer informe sobre la expulsión de extranjeros Presentado por el Sr. Maurice Kamto, Relator Especial, UN Doc. A/CN.4/581, 19 de abril de 2007.

Relator Especial para la Expulsión de Extranjeros, UN Doc. A/CN.4/573, 20 de julio de 2006, citado

Rubio Fernández, E., (2010) “Crónica de Codificación Internacional: la labor de la Comisión de Derecho Internacional”, Revista Electrónica de Estudios Internacionales, No. 19, pp. 1-79;

Rubio Fernández, E., (2014) “Crónica de Codificación Internacional: la labor de la Comisión de Derecho Internacional”, Revista Electrónica de Estudios Internacionales, No. 28, pp. 1-41.

Sorensen, M., (1975), Manual de Derecho Internacional Público, Fondo de Cultura Económica, México 